\title{
Test Plan for Demonstration of Rapid Transuranic Monitoring Laboratory
}

\author{
C. V. Mclsaac \\ C. W. Sill \\ R. J. Gehrke \\ E. W. Killian \\ K. D. Watts
}

Published June 1993

Idaho National Engineering Laboratory

EG\&G Idaho, Inc.

Idaho Falls, Idaho 83415 
Test Plan for Demonstration of Rapid Transuranic Monitoring Laboratory

EGG-WTD-10758

Prepared by

chmileare

C. V. McIsaac, Senior Scientist

Radiation Measurements and Development

Reviewed by

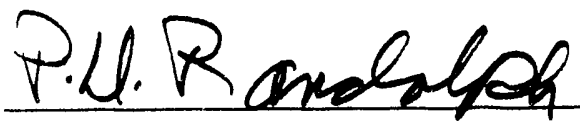

P. D. Randolph, Technical Leader, Radiation Measurements and Development

Approved by

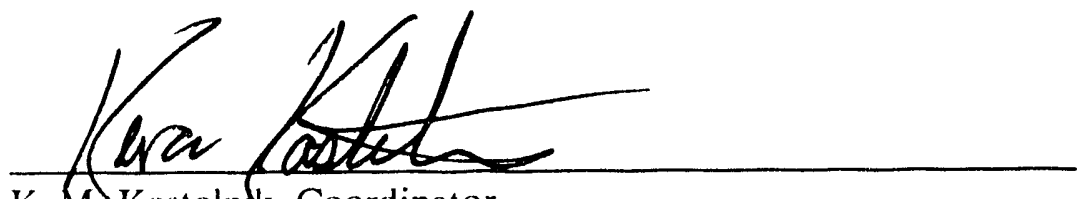

K. M. Kostelnk, Coordinator Buried Waste Integrated Demonstration

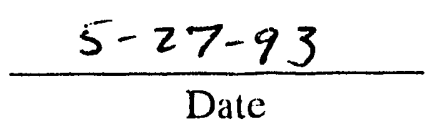

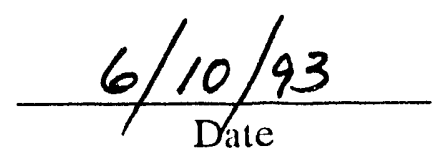

K. L. Martin, Tanager

$$
\frac{5-27-93}{\text { Date }}
$$




\begin{abstract}
This plan describes tests to demonstrate the capability of the Rapid Transuranic Monitoring Laboratory (RTML) to monitor airborne alpha-emitting radionuclides and analyze soil, smear, and filter samples for alpha- and gamma-emitting radionuclides under field conditions. The RTML will be tested during June 1993 at a site adjacent to the Cold Test Pit at the Radioactive Waste Management Complex at the Idaho National Engineering Laboratory. Measurement systems installed in the RTML that will be demonstrated include two large-area ionization chamber alpha spectrometers, an x-ray/gamma-ray spectrometer, and four alpha continuous air monitors. Test objectives, requirements for data quality, experimental apparatus and procedures, and safety and logistics issues are described.
\end{abstract}





\section{SUMMARY}

This test plan describes objectives, instrumentation, and experimental procedures to ficld test measurement systems installed in the Rapid Transuranic Monitoring Laboratory (RTML), a mobile laboratory developed at the Idaho National Engineering Laboratory (INEL) for use in characterizing radiological source terms at buried radioactive waste remediation sites. The demonstration of the RTML at the INEL is sponsored by the Buried Waste Integrated Demonstration (BWID) Program under Technical Task Plan ID121210, "BWID Contamination Control." The BWID Program develops and demonstrates new technologies for remediating buried waste at facilities throughout the U.S. Department of Energy (DOE) complex. Analytical technologies that will be tested in the field include two large-area ionization chamber alpha spectrometers, an $\mathrm{x}$-ray/gamma-ray spectrometer, and four alpha continuous air monitors (CAMs).

The DOE has a recognized need for analytical technologies that can be used to assess radiological source terms both prior to and during remediation of buried radioactive waste. Since the RTML is housed in a tractor trailer, it can be moved to the remediation site, eliminating the need for shipping samples to distant analytical laboratories. Because the RTML is equipped with only direct spectrometric analysis technologies that require minimal sample preparation, samples can be prepared for analysis and analyzed in less than 1 hour. The mobile laboratory provides a rapid, cost-effective means of characterizing and monitoring radioactive waste remediation sites for alphaand gamma-emitting contaminants.

During fiscal year 1990 to 1992 , a number of promising measurement methods and systems were evaluated for possible use in monitoring transuranic (TRU) concentrations in ambient air and in soil, smear, and dust samples collected during remediation of buried radioactive waste. These evaluations demonstrated that the alpha CAM used at Argonne National Laboratory-West (ANL-W) had a sensitivity for airborne ${ }^{239} \mathrm{Pu} 10$ to 20 times better than the sensitivities of four commercial alpha CAMs that were also tested. Six of the ANL-W alpha CAMs were fabricated during FY-92, and four of them are now installed in the alpha CAM sampling stations that are operated remotely from the RTML. Direct alpha spectrometry with a large-area ionization chamber and $x$-ray/gamma-ray spectrometry with a high-resolution thin-window germanium spectrometer were shown to be rapid, sensitive methods for the measurement of TRU isotopes on smears and in soil and dust samples. The two analysis techniques do not require elaborate sample preparation or time-consuming chemical separations; soil samples are only dried and sieved before analysis. Smears and filters are analyzed directly without any sample preparation.

The RTML consists of two separate trailers that are powered from a $50 \mathrm{~kW}$ diesel gencrator. One trailer, $2.4 \mathrm{~m}$ wide $\times 7.3 \mathrm{~m}$ long $(8 \times 24 \mathrm{ft})$, houses the sample preparation laboratory that is equipped with a Class $\mathrm{A}$ hood, oven, sieving equipment, analytical balance, and sample containers. Samples will be received and prepared for analysis in this trailer. The second trailer, $2.4 \mathrm{~m}$ wide $\times$ $14.6 \mathrm{~m}$ long $(8 \times 48 \mathrm{ft})$, houses the computer terminal used to control the or erition of the lour alpha CAMs that will be installed in the Cold Test Pit: two Ordela large-area im zation chamber alpha spectrometers, a thin-window $x$-ray/gamma-ray spectrometer installed in an autumatic sample changer, a VAX 4000 model 100 computer, and computer terminals and printers used to display and generate reports of analysis results. The RTML will be moved to a location adjacent to the RWMC Cold Test Pit at the INEL and will be demonstrated during June 1993 in conjunction with a remote retrieval demonstration. 
Although the field tests are being conducted at the Cold Test Pit and the bulk of the samples will be taken from the vicinity of the Cold Test Pit, some spiked samples of known activity will be introduced into the sample processing stream. The operators in the counting trailer will be unaware of which samples contain known activity concentrations. Plutonium, americium, and gamma-ray emitting radionuclides will be introduced to the process stream. The results of these analyses will be compared to the known values and will be the basis of evaluating the analysis accuracy and precision of counting unknown samples.

Samples that are "free" of radioactivity and those that have been spiked will be counted to demonstrate the capability of the RTML to operate on generator power, acquire quality data, and obtain accurate results (measured activity for the spiked samples and no statistically significant activity for the "cold" samples for all types of samples, i.e., radioactive and nonradioactive and smear, and air filter samples). Since the purpose of this field test does not involve sampling techniques, the source of "nonradioactive" soil samples will not be discussed in this test plan except to acknowledge that soil from the vicinity of the Cold Test Pit will be used to prepare "nonradioactive" samples.

During the demonstration, ambient air over the test pit and samples of soil and dust from the pit will be analyzed for alpha- and gamma-emitting radionuclides using the RTML. The primary objective of the field test of the RTML is to demonstrate and evaluate the capability of the RTML to analyze soil, smear, and filter samples for ${ }^{239} \mathrm{Pu},{ }^{241} \mathrm{Am}$, and gamma-cmitting radionuclides such as ${ }^{60} \mathrm{Co}$ and ${ }^{137} \mathrm{Cs}$.

Data quality objectives of the field demonstration of the RTML focus primarily on determining the sensitivity of each measurement system for detection of TRU and/or fission product radionuclides using counting times of 30 minutes or less. Technical performance goals include producing field-deployable measurement systems that have the following sensitivities: (a) the alpha CAM system will have a sensitivity for airborne TRU isotopes that is superior to the sensitivity of 8 derived air concentration (DAC) hours required by DOE Order 5480.11, "Radiation Protection for Occupational Workers," (b) the large-area ionization chamber alpha spectrometer will be capable of analyzing soil samples in 30 minutes or less with a lower limit of detection (LLD) of $50 \mathrm{pCi} / \mathrm{g}$ for TRU isotopes, and (c) the x-ray/gamma-ray spectrometer will be capable of analyzing soil samples in 30) minutes or less with LLDs of $50 \mathrm{pCi} / \mathrm{g}$ for plutonium, $1 \mathrm{pCi} / \mathrm{g}$ for ${ }^{241} \mathrm{Am}$, and $4 \mathrm{pCi} / \mathrm{g}$ for gamma-emilting radionuclides such as ${ }^{60} \mathrm{Co}$ and ${ }^{137} \mathrm{Cs}$. The software codes used to control the measurement systems and analyze spectral data will reside on a VAX 4000 model 100 computer installed in the RTML analysis trailer.

The definition of lower limit of detection given by Currie will be used to calculate the sensitivities of the analytical instrumentation. His equation for paired observations of sample and background with a probability of 0.05 that activity will be detected when none is present or that activity will not be detected when in fact it is present is

a. L. A. Currie, "Limits for Qualitative Detection and Quantitative Determination," Anal Chem 40:586-59.3, 1968. 
$\mathrm{LLD}=2.71+4.66 \mathrm{~B}^{1 / 2}$

In terms of concentration in soil, expressed as $\mathrm{pCi} / \mathrm{g}$, the equation becomes

$\operatorname{LLD}=\frac{2.71+4.66 \mathrm{~B}^{1 / 2}}{2.22 \cdot \mathrm{T} \cdot \epsilon \cdot \mathrm{Y} \cdot \mathrm{M}}$

where

$2.22=$ number of disintegrations per minute per $\mathrm{pCi}$

B = total number of background counts in the region of interest (counts)

$\mathrm{T}=$ counting time (minutes)

$\epsilon \quad=\quad$ absolute counting efficiency (counts per disintegration)

$\mathrm{Y}=$ fractional recovery in the region of interest

$\mathrm{M} \quad=\quad$ mass of sample $(\mathrm{g})$. 


\section{CONTENTS}

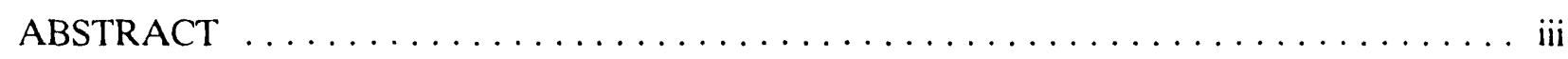

SUMMARY $\ldots \ldots \ldots \ldots \ldots \ldots \ldots \ldots \ldots \ldots \ldots \ldots \ldots \ldots \ldots \ldots \ldots \ldots \ldots$

ACRONYMS $\ldots \ldots \ldots \ldots \ldots \ldots \ldots \ldots \ldots \ldots \ldots \ldots \ldots \ldots \ldots \ldots \ldots \ldots \ldots \ldots \ldots \ldots \ldots \ldots$

1. INTRODUCTION $\ldots \ldots \ldots \ldots \ldots \ldots \ldots \ldots \ldots \ldots \ldots \ldots \ldots \ldots \ldots \ldots$

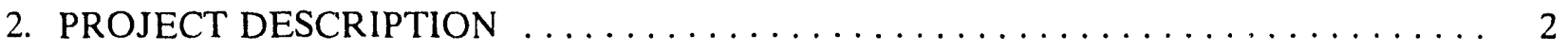

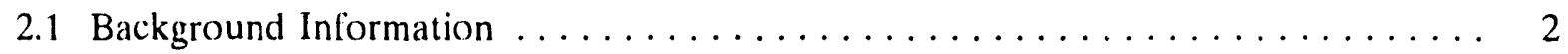

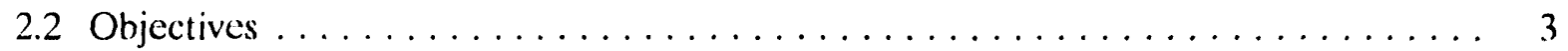

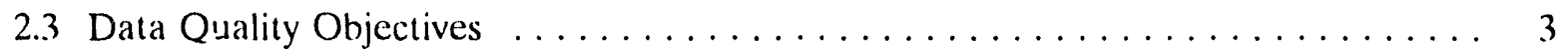

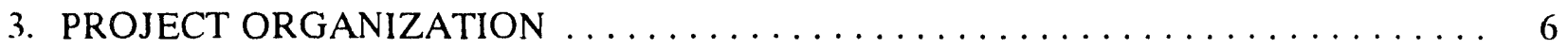

4. APPARATUS AND EQUIPMENT $\ldots \ldots \ldots \ldots \ldots \ldots \ldots \ldots \ldots \ldots \ldots \ldots \ldots$

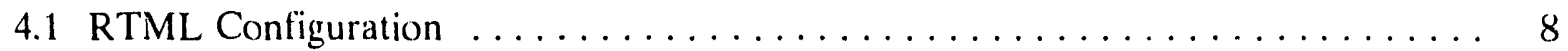

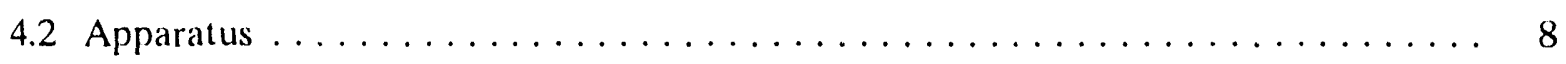

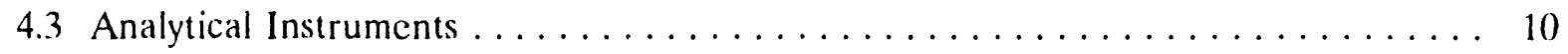

4.3.1 Large-Area Ionization Chamber Alpha Spectrometer . . . . . . . . . . . . 10

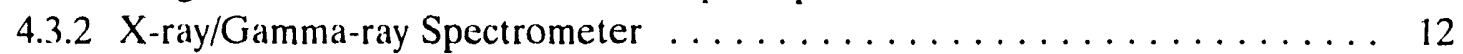

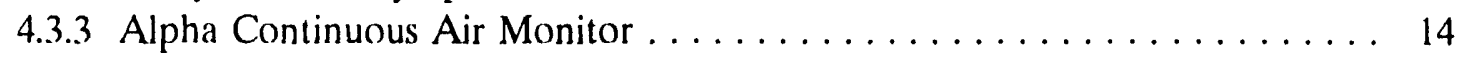

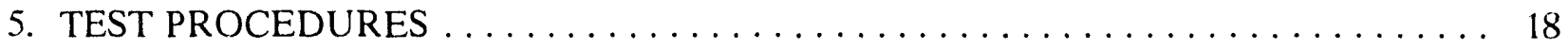

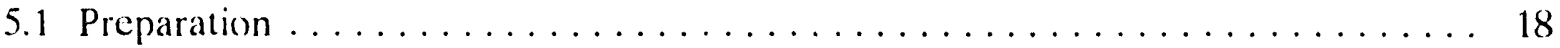

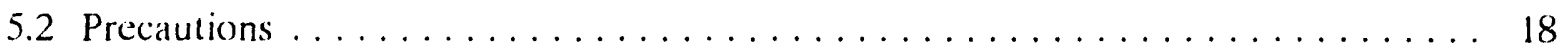

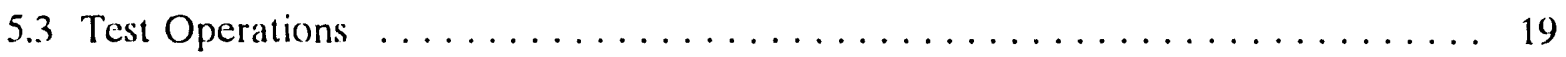

5.3.1 Sample Collection . . . . . . . . . . . . . . . . . . . . 19

5.3.2 Sample Pretreatment ......................... 20

5.3.3 Sample Preparation for Counting $\ldots \ldots \ldots \ldots \ldots \ldots \ldots \ldots \ldots \ldots$. . . . . . .

5.3 .4 Sample Analysis .......................... 21

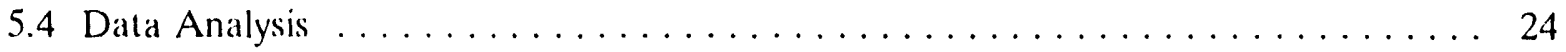


6. SAMPLE CONTROL AND DOCUMENT MANAGEMENT $\ldots \ldots \ldots \ldots \ldots \ldots \ldots$

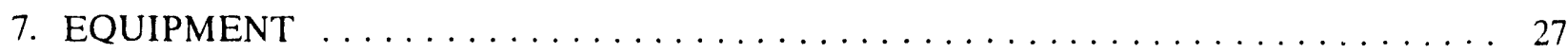

7.1 Sample Collection $\ldots \ldots \ldots \ldots \ldots \ldots \ldots \ldots \ldots \ldots \ldots \ldots \ldots \ldots \ldots$

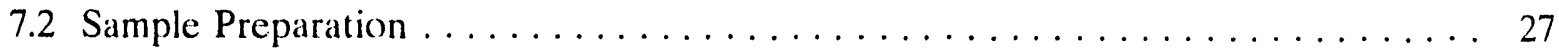

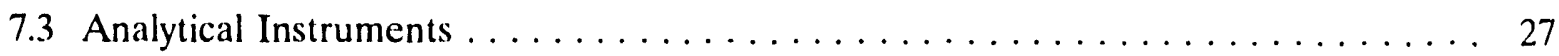

7.3.1 Large-area Ionization Chamber Spectrometer . . . . . . . . . . . . . 27

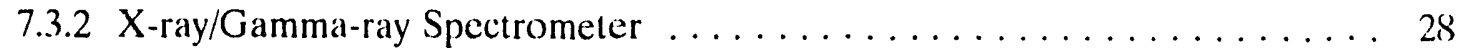

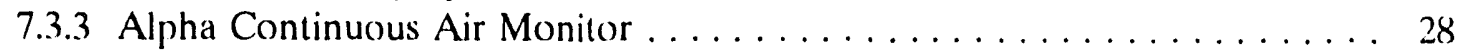

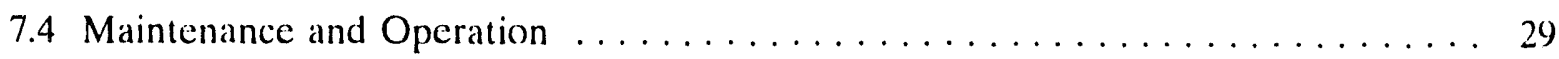

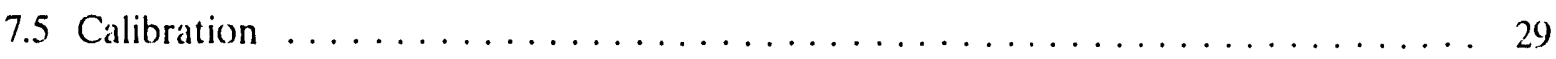

7.5.1 Large-area Ionization Chamber Alpha Spectrometer . . . . . . . . . . . . . 29

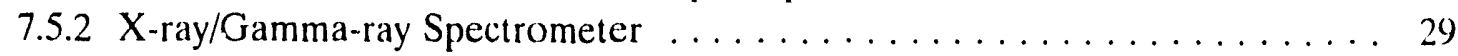

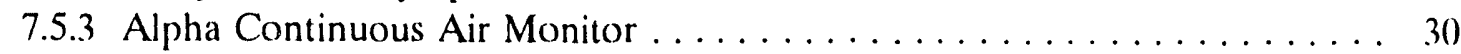

8. ANALYTICAL PROCEDURES $\ldots \ldots \ldots \ldots \ldots \ldots \ldots \ldots \ldots \ldots \ldots \ldots \ldots \ldots$

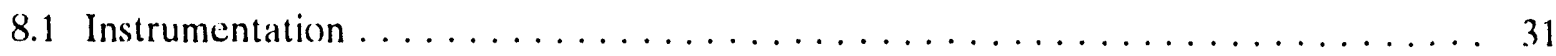

8.1.1 Large-area Ionization Chamber Alpha Spectrometer . . . . . . . . . . 31

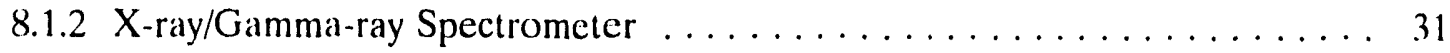

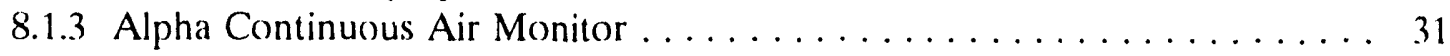

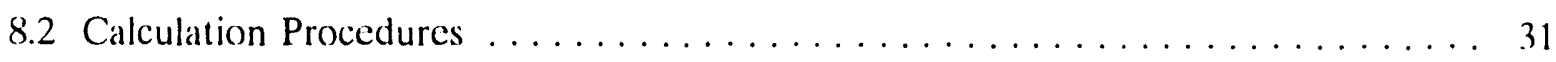

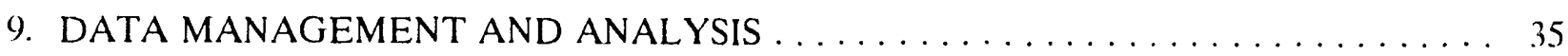

9.1 Reduction, Validation, and Recording $\ldots \ldots \ldots \ldots \ldots \ldots \ldots \ldots \ldots$

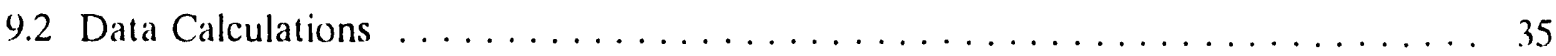

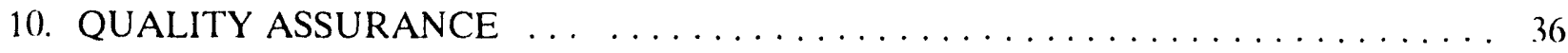

10.1 Quantitative Quality Assurance Objectives . . . . . . . . . . . . 36

10.2 Replicate Blanks . . . . . . . . . . . . . . . . . .

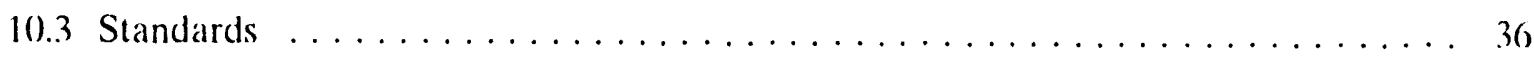

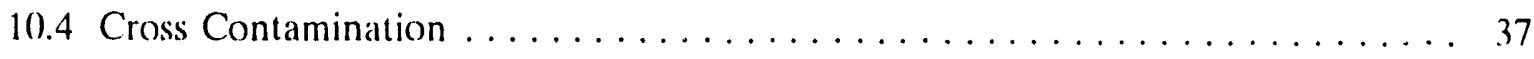


11. SAFETY, TRAINING, AND LOGISTICS $\ldots \ldots \ldots \ldots \ldots \ldots \ldots \ldots \ldots$

11.1 Radiological Safety and Training $\ldots \ldots \ldots \ldots \ldots \ldots \ldots \ldots \ldots \ldots$

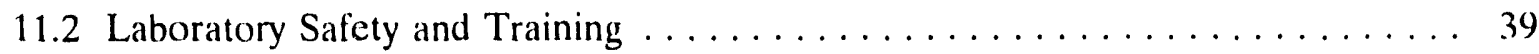

11.3 Waste Management Practices and Training $\ldots \ldots \ldots \ldots \ldots \ldots \ldots \ldots \ldots$

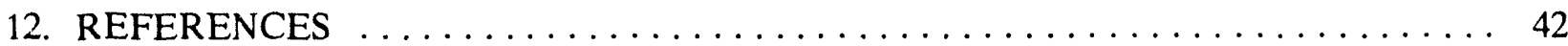

\section{FIGURES}

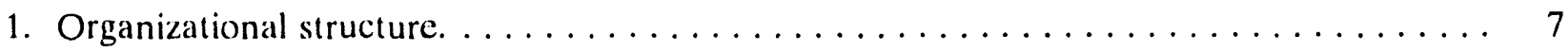

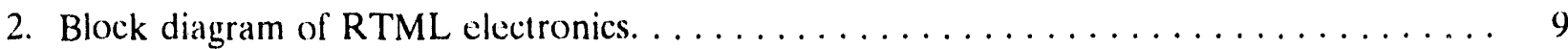

3. Cut-away view of Ordela large-area ionization chamber. $\ldots \ldots \ldots \ldots \ldots \ldots \ldots \ldots$

4. Block diagram of $\mathrm{x}$-ray/gamma-ray spectrometer electronics. $\ldots \ldots \ldots \ldots \ldots \ldots \ldots$

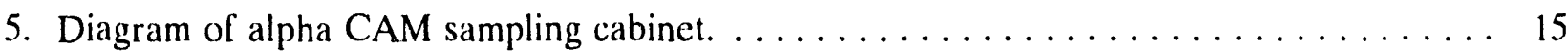

6. Block diagram of the alpha CAM electronics cabinet. $\ldots \ldots \ldots \ldots \ldots \ldots \ldots$

7. Ionization chamber gas and vacuum connections. $\ldots \ldots \ldots \ldots \ldots \ldots \ldots \ldots \ldots \ldots$

\section{TABLE}

1. LLD concentrations for $x$-ray/gamma-ray spectrometer $\ldots \ldots \ldots \ldots \ldots \ldots \ldots \ldots$ 



\section{ACRONYMS}

\begin{tabular}{|c|c|}
\hline $\mathrm{ADC}$ & Analog-to-digital converter \\
\hline AIM & Acquisition interface module \\
\hline ANL-W & Argonne National Laboratory-West \\
\hline BWID & Buried Waste Intergrated Demonstration \\
\hline CAM & Continuous air monitor \\
\hline DAC & Derived air concentration \\
\hline DOE & U.S. Department of Energy \\
\hline FY & Fiscal year \\
\hline $\mathrm{HP}$ & Health physics \\
\hline INEL & Idaho National Engineering Laboratory \\
\hline LLD & Lower limit of detection \\
\hline MCA & Multichannel analyzer \\
\hline NIM & Nuclear instrument module \\
\hline N\&RP & Nuclear and Radiological Physics \\
\hline OSHA & Occupational Safety and Health Administration \\
\hline RADCON & Radiological control \\
\hline $\mathrm{RCT}$ & Radiological controls technician \\
\hline $\mathrm{RM} \& \mathrm{D}$ & Radiation Measurements and Development \\
\hline RML & Radiation Measurements Laboratory \\
\hline ROI & Region of interest \\
\hline RTML & Rapid Transuranic Monitoring Laboratory \\
\hline
\end{tabular}


RWMC Radioactive Waste Management Complex

TRU Transuranic 


\section{Test Plan for Demonstration of Rapid Transuranic Monitoring Laboratory}

\section{INTRODUCTION}

This test plan describes objectives, instrumentation, and experimental procedures to field test measurement systems installed in the Rapid Transuranic Monitoring Laboratory (RTML), a mobile laboratory developed at the Idaho National Engineering Laboratory (INEL) for use in characterizing radiological source terms at buried radioactive waste remediatior: sites. Analytical technologies that will be tested in the field include two large-area ionization chamber alpha spectrometers, an $\mathrm{x}$-ray/gamma-ray spectrometer, and four alpha continuous air monitors (CAMs).

The first technology involves direct alpha spectrometry in a $35 \mathrm{~cm}$ diameter ionization chamber. Soil samples are dried, sieved, finely ground and, with each sample, $100 \mathrm{mg}$ of the ground soil is suspended in an ethanol/water solution that is sprayed onto a $25 \mathrm{~cm}$ diamcter stainless steel pan. The pan is positioned in a recess in the bottom of the ionization chamber for counting. Air dusts are collected with a high-volume air sampler on $20 \times 25 \mathrm{~cm} 8 \times 10 \mathrm{in}$.) membrane filters with $1.0 \mu \mathrm{m}$ pores. In the case of air filters, no sample preparation is required before counting in the ionization chamber. A milled cutout in the sample plate is used to position the air filter reproducibly inside the ionization chamber for counting.

The second technology involves the simultaneous measurement of L-shell $x$-rays and gamma rays using a high-resolution germanium spectrometer equipped with a thin entrance window. Soil samples are dried, sieved to remove any particles larger than $300 \mu \mathrm{m}$, and with each sample, $10 \mathrm{~g}$ of sieved soil is loaded into a thin plastic sample container having a diameter slightly larger than the diameter of the germanium crystal and counted with the sample container positioned near the lace of the end-cap of the germanium detector. Smears and air filters are centered in the same plastic sample container used to analyze soil samples and are analyzed directly using a reproducible counting geometry.

The third technology involves the direct measurement of alpha activity in air by pulse-height analysis of the alpha activity removed from air that is sampled. The measurement of airborne alpha-emitting radionuclides is performed by pulling a continuous sample of ambient air through a two-stage virtual impactor and then through a filter having a pore size small enough to trap aerosolized particles. The virtual impactor removes a large fraction of the naturally occurring radon daughter isotopes from the airstream before it passes through the sample filter. The alpha-emitting radionuclides are attached to the aerosol particles that are trapped by the filter. Alpha activity on the filter is measured by a solid-state silicon detector positioned about $3 \mathrm{~mm}$ from the influent face of the filter.

The practical application of these technologies in determining radiological source terms at buricd radioactive waste remediation sites will be tested experimentally during June 1993 in conjunction with a remote retrieval demonstration conducted at the Radioactive Waste Management Complex (RWMC) at the INEL. 


\section{PROJECT DESCRIPTION}

The demonstration of the RTML at the INEL is sponsored by the Buried Waste Integrated Demonstration (BWID) Program under Technical Task Plan ID121210, "BWID Contamination Control." The BWID Program develops and demonstrates new technologics for application to remediation of buried waste at facilities throughout the U.S. Department of Energy (DÚE) complex.

The DOE has a recognized need for analytical technologies that can be used in the field to assess radiological source terms both before and during remediation of buried adioactive waste. Existing field-deployable technologies do not have sufficient sensitivities for alpha- and gamma-emitting radionuclides. Consequently, samples collected from a remediation site must be shipped to a laboratory for wet-chemical analysis. Analytical techniques currently used at such laboratories to determine transuranic (TRU) isotopes and radiostrontium require rigorous sample pretreatment and time consuming radiochemical separation of the radionuclides of interest before analysis. Because the RTML is housed in a trailer, it can be moved to the remediation site, eliminating the need for shipping samples to analytical laboratories. Using the RTML, high-priority samples can be analyzed promptly at the remediation site. Because the RTML is equipped with only direct spectrometric analysis technologies that require minimal or no sample preparation, samples can be prepared for analysis and analyzed in less than 1 hour. The mobile laboratory provides a rapid, cost-effective means of characterizing and monitoring radioactive waste remediation sites for alphaand gamma-emitting contaminants.

\subsection{Background Information}

During fiscal year (FY)-90 to -92 a number of promising measurement methods and systems were evaluated for possible use in monitoring TRU concentrations in ambient air and in soil, smear, and dust samples collected during remediation of buried radioactive waste. ${ }^{1,2,3}$ The sensitivities of five different alpha CAMs for airborne ${ }^{239} \mathrm{Pu}$ were determined experimentally. ${ }^{4,5,6,7,8}$ The following six methods of making quantitative measurements of TRU contamination on smears and in soil and dust samples were also evaluated experimentally: (a) alpha liquid scintillation spectrometry, (b) rapid radiochemical separation followed by high-resolution alpha spectrometry, (c) gamma-ray spectrometry, (d) $x$-ray/gamma-ray spectrometry, (e) direct alpha spectrometry using a large-area ionization chamber, and (l) gross alpha counting using a scintillation detector. ${ }^{0,9,10,11,12}$

These evaluations demonstrated that the alpha CAM used at Argonnc National Laboratory-West (ANL-W) had a sensitivity for airborne ${ }^{239} \mathrm{Pu} 10$ to 20 times better than the four commercial alpha CAMs that were also tested. Six of the ANL-W alpha CAMs were fabricated during FY-92, and four of them are now installed in the alpha CAM sampling stations that are operated remotely from the RTML. Direct alpha spectrometry with a large-area ionization chamber and $\mathrm{x}$-ray/gamma-ray spectrometry with a high-resolution, thin-window germanium spectrometer were shown to be rapid (count times 5.30 minutes) sensitive methods for the measurement of TRU isotopes on smears and in soil and dust samples. The two analysis techniques do not require elaborate and time-consuming chemical separations; soil samples are only dried and sieved before analysis, and smears and filters are analyzed directly without any sample preparation. 
Two large-area ionization chamber alpha spectrometers, a thin-window germanium spectromeler installed in an automatic sample changer, four alpha CAMs, and a VAX 4000) model 10) computer were installed in the RTML during March and April 1993. The RTML will be moved to a location adjacent to the Cold Test Pit at the INEL and will be demonstrated during June 1993 in conjunction with a remote retrieval demonstration.

\subsection{Objectives}

During the demonstration, ambient air over the test pit and samples of soil and dust from the pit will be analyzed for alpha- and gamma-emitting radionuclides using the RTML. The primary objective of the field test of the RTML is to demonstrate and evaluate the capability of the RTML to analyze soil, smear, and filter samples for ${ }^{239} \mathrm{Pu},{ }^{241} \mathrm{Am}$, and gamma-emitling radionuclides such as ${ }^{60} \mathrm{Co}$ and ${ }^{137} \mathrm{Cs}$. Spiked samples will be introduced into the sample stream before being delivered to the counting trailer. The spiked samples will contain both quantifiable amounts of activity and amounts that are near the claimed detection limit. To achieve this objective, the following specific tasks will be performed.

- Test the performance and reliability of instrumentation installed in the RTML under field conditions when power is supplied from a diesel generator.

- For each measurement system, determine the lower limit of detection concentration/activity for each of the alpha- and gamma-emitting radionuclides of interest and the precision and accuracy achieved with minimal counting times.

- Determine the sample throughput rate for each measurement system and the total number of samples that can be analyzed per day.

- Determine the cost of operating the RTML.

\subsection{Data Quality Objectives}

The intermediate-range technical pertormance objective of this project is to produce a field-deployable, mobile laboratory that will provide Environmental Restoration and Waste Management Programs throughout the DOE complex with the capability to monitor airborne TRU isotopes and analyze soil, smear, and air tilter samples for alpha- and gamma-emilting radionuclides using direct spectrometric methods that are rapid, sensitive, and cost-effective.

Data quality objectives of the ficld demonstration of the RTML focus primarily on determining the sensitivity of each measurement system for detection of TRU and/or fission product radionuclides using counting times of 30 minutes or less. Technical performance goals include producing lield-deployable measurement systems that will have the following sensitivities: (a) alpha CAM system will have a sensitivity for airborne TRU isotopes that is superior to the sensitivity of 8 derived air concentration (DAC) hours required by DOE Order 5480.11, "Radiation Protection for Occupational Workers," (b) large-area ionization chamber alpha spectrometer will be capable of analyzing soil samples in 30 minutes or less with a lower limit of detection (LLD) of $50 \mathrm{pCi} / \mathrm{g}$ for TRU isotopes and air samples with an LLD of $0.1 \mathrm{DAC}-\mathrm{h}$, and (c) $\mathrm{x}$-ray/gamma-ray spectrometer will 
be capable of analyzing soil samples in 30 minutes or less with LLDs of $50 \mathrm{pCi} / \mathrm{g}$ for plutonium, 1 $\mathrm{pCi} / \mathrm{g}$ for ${ }^{241} \mathrm{Am}, 4 \mathrm{pCi} / \mathrm{g}$ for ${ }^{60} \mathrm{Co}$, and $3 \mathrm{pCi} / \mathrm{g}$ for ${ }^{137} \mathrm{Cs}$. LLD goals for the $\mathrm{x}$-ray/gamma-ray spectrometer for other gamma-emilting radionuclides are given in Table 1. The solitware codes used to control the measurement systems and analyze spectral data will reside on a VAX 4000) model 100) computer installed in the RTML analysis trailer.

Table 1. LLD concentrations for $x$-ray/gamma-ray spectrometer.

\begin{tabular}{|c|c|c|}
\hline Radionuclide & $\begin{array}{l}\text { Dose equivalent } \\
\text { of } 100 \mathrm{mrem} / \text { year } \\
(\mathrm{pCi} / \mathrm{g})^{a}\end{array}$ & $\begin{array}{c}\text { LLD } \\
(p C i / g)^{\prime}\end{array}$ \\
\hline${ }^{54} \mathrm{Mn}$ & 10 & $4^{*}$ \\
\hline${ }^{57} \mathrm{Co}$ & 200 & $2^{*}$ \\
\hline${ }^{58} \mathrm{Co}$ & 30 & $4^{*}$ \\
\hline${ }^{60} \mathrm{Co}$ & 4 & 4 \\
\hline${ }^{106} \mathrm{Ru}$ & 60 & $30 *$ \\
\hline${ }^{125} \mathrm{Sb}$ & 20 & $10 *$ \\
\hline${ }^{134} \mathrm{Cs}$ & 6 & $3^{*}$ \\
\hline${ }^{137} \mathrm{Cs}$ & 10 & 3 \\
\hline${ }^{144} \mathrm{Ce}$ & 300 & 2()$^{*}$ \\
\hline${ }^{152} \mathrm{Eu}$ & 10 & $10^{*}$ \\
\hline${ }^{154} \mathrm{Eu}$ & 7 & $12^{*}$ \\
\hline${ }^{155} \mathrm{Eu}$ & 400 & $8^{*}$ \\
\hline${ }^{227} \mathrm{Ac}$ & 7 & $20^{*}$ \\
\hline${ }^{232} \mathrm{U}$ & 3 & $6^{*}$ \\
\hline${ }^{2.39} \mathrm{Pu}$ & 300 & 50 \\
\hline${ }^{241} \mathrm{Am}$ & 80 & 1 \\
\hline
\end{tabular}

a. Concentration in soil corresponding to an effective dose equivalent of 100 mrem in first year after release offsite. Taken from Table 14 of Reference 13.

b. Lower limit of detection concentration in soil for a $12 \mathrm{~g}$ sample counted for 30 minutes and calculated at the $95 \%$ confidence level. Values with an asterisk are estimated LLDs. All other values are measured L.LDs. 
DOE Order 5400.5, "Radiation Protection of the Public and the Environment," specifies that the basic public dose limits for exposure to residual radioactive material are $100 \mathrm{mrem}$ effective dose equivalent in a year. Soil concentration guides derived from the $100 \mathrm{mrem} / \mathrm{year}$ criterion for the farming scenario are reported in Reference 13. The concentration in soil corresponding to an effective dose equivalent of $100 \mathrm{mrem}$ in the first year after release of the remediation site is $4 \mathrm{pCi} / \mathrm{g}$ ${ }^{60} \mathrm{Co}, 50 \mathrm{pCi} / \mathrm{g}{ }^{90} \mathrm{Sr}, 10 \mathrm{pCi} / \mathrm{g}{ }^{137} \mathrm{Cs}, 300 \mathrm{pCi} / \mathrm{g}{ }^{239} \mathrm{Pu}$, and $80 \mathrm{pCi} / \mathrm{g}{ }^{241} \mathrm{Am}^{13}$. The measurable performance goals of the demonstration include achieving LLDs for soil samples that are at or below these $100 \mathrm{mrem} / \mathrm{year}$ concentrations.

In the case of the $x$-ray/gamma-ray spectrometer, the total uncertainty reported with measured activities will include components with the following minimum uncertainties: calibration $( \pm 5 \%)$, sample mass or volume $( \pm 1 \%)$, cascade coincidence gamma-ray summing $( \pm 10 \%)$, and reproducibility of counting geometry $( \pm 3 \%)$. Since the LXRAY code does not currently propagate all uncertainty components in determining the uncertainty due to counting statistics, a value of $\pm 10 \%$ will be used for activity concentrations that are a factor of three above the quoted LLD, and a value of $\pm 3 \%$ will be used for activity concentrations that are a factor of 20 above the guoted LLD. These values werc determined empirically from the analysis of a number of samples containing known plutonium activities. 


\section{PROJECT ORGANIZATION}

The organizational affiliations and responsibilities of the key personnel involved in the demonstration of the RTML are shown in Figure 1. Personnel from the Radiation Measurements and Development (RM\&D) Unit of EG\&G Idaho, Inc. will collect and deliver samples to the RTML and will also prepare samples for analysis. During the demonstration, personnel from the RM\&D and the Nuclear and Radiological Physics (N\&RP) Units of EG\&G Idaho, Inc. will operate all RTML analytical instruments. Principal investigators will be responsible for their individual analysis methodologies. Overall arrangements of the Cold Test Pit demonstration are the responsibility of C. V. McIsaac.

The radiological controls technician (RCT) will be responsible for radiological monitoring of the area during the demonstration. The RCT will assist in monitoring samples delivered to the RTML and will verify that all personnel are wearing proper dosimetry. 


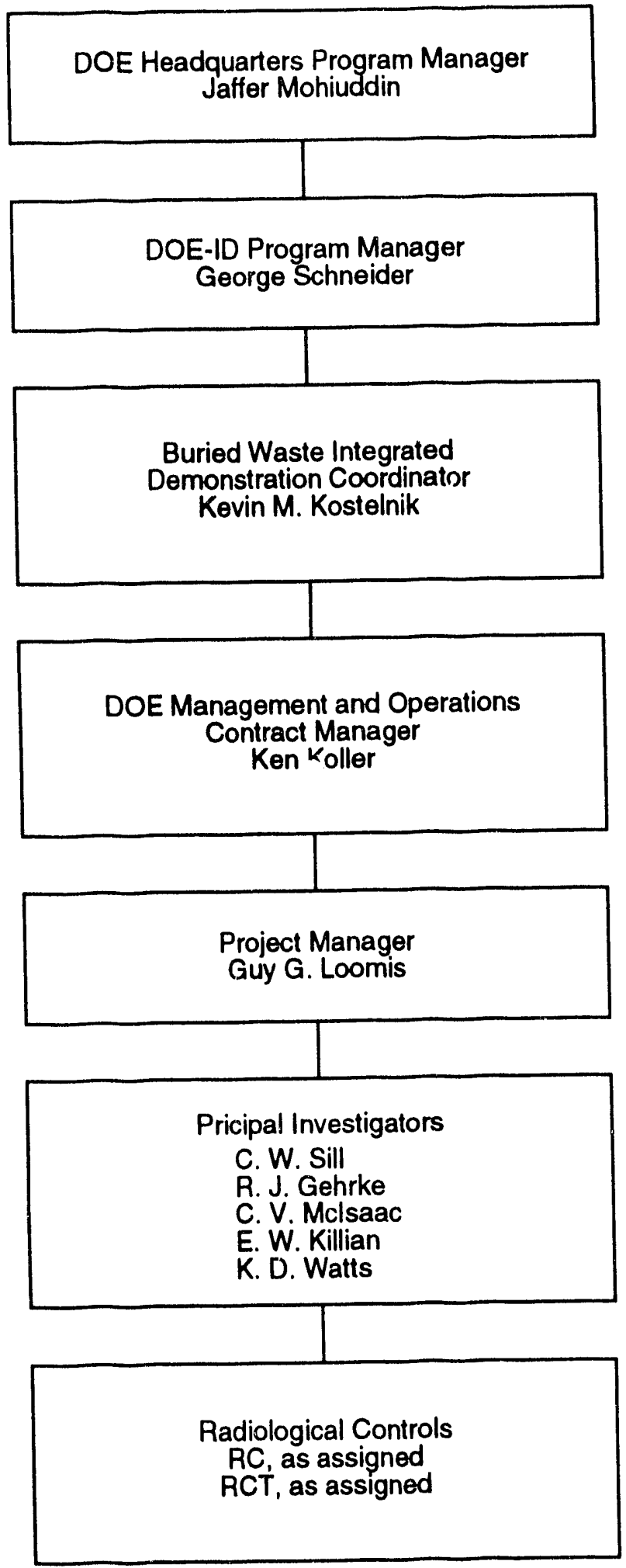

Y93 0170

Figure 1. Organizational structure. 


\section{APPARATUS AND EQUIPMENT}

This section describes the main structural components of the RTML, equipment used to prepare samples for inalysis, laboratory instruments used to analyze samples, and type of data that will be collected during the demonstration.

\subsection{RTML Configuration}

The RTML consists of two separate trailers and mobile $5,12.5$, and $20 \mathrm{~kW}$ diesel generators. One trailer, $2.4 \mathrm{~m}$ wide $\times 7.3 \mathrm{~m}$ long $(8 \times 2.4 \mathrm{ft})$, houses the sample preparation laboratory that is equipped with a Class $\mathrm{A}$ hood, oven, sieving equipment, analytical balance, and sample containers. Samples will be received and prepared for analysis in this trailer. The second trailer, $2.4 \mathrm{~m}$ wide $\times$ $14.6 \mathrm{~m}$ long $(8 \times 48 \mathrm{ft})$, houses the analytical instruments and computer used to analyze soil, smear, and filter samples and also houses the computer terminal used to control the operition of the four alpha CAMs that will be installed inside the Cold Test Pit enclosure. During the deisonstration, both trailers and diesel generator will be parked adjacent the Cold Test Pit.

\subsection{Apparatus}

To facilitate analyzing samples as quickly as possible following their collection, the RTML is equipped with four alpha CAMs, two large-area ionization chamber alpha spectrometers, a thin-window germanium $x$-ray/gamma-ray spectrometer installed in an automatic sample changer, a VAX 4000 model 100 computer, and associated computer terminals, monitors, and printers. A block diagram of the instrumentation and associated electronics that will be installed in the RTML analysis trailer and inside the tent enclosing the pit is shown in Figure 2.

As shown in Figure 2, four alpha CAMs will be installed inside the tent covering the pit to monitor concentrations of airborne TRU isotopes. The four CAMs will be controlled from and spectral data transmitted to the VAX computer installed in the RTML using an Ethernet coaxial cable link between the VAX computer and two acquisition interlace modules (AIMs) installed in two CAM electronics cabinets. Each electronics cabinet will house the electronics needed to operate two alpha CAMs. The current spectrum and status of each of the four CAMs will be displayed on an $X$-terminal monitor in the RTML. For each CAM, a plot of the concentrations of airborne TRU isotopes during the previous 24 hours will be displayed on the same monitor used to display CAM status. Hard copies of tabulations and plots of the concentrations of airborne TRU isolopes over any given time period will be prepared using a laser printer.

The two large-area ionization chamber alpha spectrometers and thin-window, germanium $x$-ray/gamma-ray spectrometer will be controlled from and spectral data transmitted to the VAX computer using an Ethernet link between the VAX computer and two AIMs. The x-ray/gamma-ray spectrometer sample changer will be controlled by the VAX computer through the terminal server.

The high-volume air sampler used to obtain samples of airborne dust for analysis with the large-arca ionization chamber alpha spectrometer is a model HV-1SH manufactured by $\mathrm{F}$ \& $\mathrm{J}$ Specialty Products, Inc., Miami Springs, Florida. The sampler is equipped with a flowmeter calibrated for a range from 0.3 to $1.6 \mathrm{~m}^{3} /$ minute $(10$ to $55 \mathrm{cfm}$ ) of air and can be used with filler holders for 


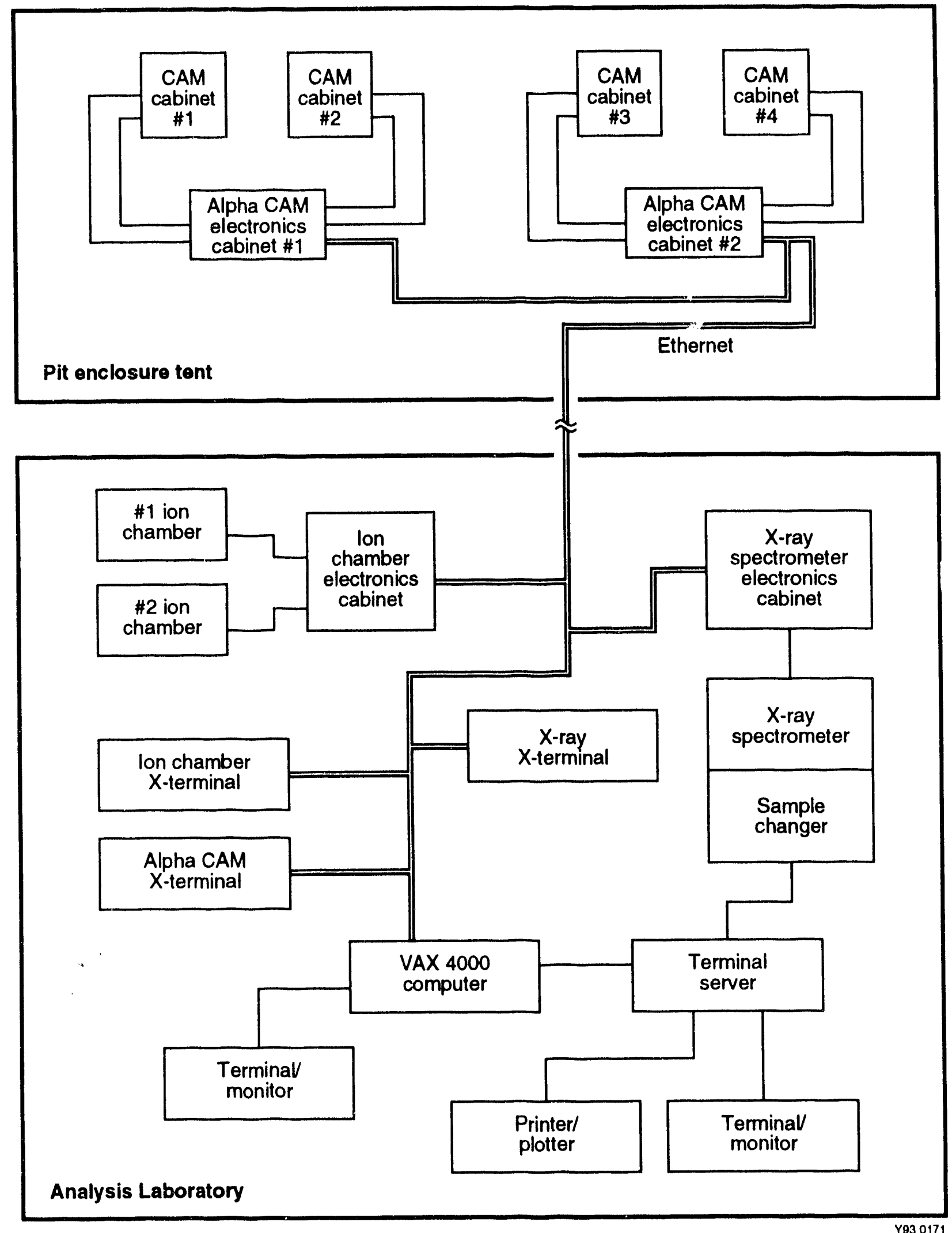

Figure 2. Block diagram of RTML electronics. 
both $10-\mathrm{cm}$ circular filters with an effective area $9 \mathrm{~cm}$ in diameter and $20 \times 25-\mathrm{cm}$ rectangular filters with an elfective area of $18 \times 2$ ? $\mathrm{cm}$. The no-load sampling rate is about $2.7 \mathrm{~m}^{3} /$ minute (97 clim) while the rate with $20 \times 25-\mathrm{cm}$ membranc lilters is about $1.1 \mathrm{~m}^{3} /$ minule $(38 \mathrm{clm}$ ) with $1.2 \mu \mathrm{m}$ pore-size Versapor 1200$)$ tilters and about $0.5 \mathrm{~m}^{3} /$ minute $(16 \mathrm{ctm})$ with $0.8-\mu \mathrm{m}$ pore-size Versapor 800 and $0.45-\mu \mathrm{m}$ pore-size Versapor 450T filters. The sampler is equipped with a cooling fan in the motor housing so that the motor does not depend solely on the air being drawn through the filter for cooling.

To disperse prepared soil samples onto the large counting planchet used with the gridded ionization counter, a $10-\mathrm{mL}$ all-glass, air-operated hand sprayer (Kontes, Vincland, New Jersey, No. 422550) is used to spray a suspension of the finely ground soil uniformly over the $25 \mathrm{~cm}$ diameter stainless-steel sample pan.

\subsection{Analytical Instruments}

\subsubsection{Large-Area Ionization Chamber Alpha Spectrometer}

Two custom-built gridded ionization chambers (Ordela, Inc., Oak Ridge, Tennessee, models $8200 \mathrm{~A}$ and $8210 \mathrm{~A}$ ) similar to those built by others ${ }^{14,15,16,17}$ are used with a low-noise preamplifier, linear amplifier, power supply, and VAX computer for data accumulation and analysis.

A cutaway view of the ionization chamber is shown in Figure 3. The ionization chamber is constructed of nickel-plated mild steel of suitable thickness to permit pressurization of the chamber 10 $100 \mathrm{kPa}$ above atmospheric pressure, which is the pressure used during counting. Both chambers have an inside diameter of $34 \mathrm{~cm}$ and internal height of $21.7 \mathrm{~cm}$. Thus, the counting gas volumes of the two chambers are both about $20 \mathrm{~L}$. A pressure-relicf valve and vacuum/pressure gauge are installed in the top of each chamber. The access port of each chamber is sealed by a drawer-seal assembly that slides in and out of the port. The sample holder has milled cutouts to hold both $25.4-\mathrm{cm}$ circular pans and $20 \times 25-\mathrm{cm}$ rectangular filters. The circular sample pans are made from $0.86 \mathrm{~mm}$ thick mirror-finish stainless steel. Each pan is $3 \mathrm{~mm}$ deep and has a surface area of $507 \mathrm{~cm}^{2}$. The $20 \times 25-\mathrm{cm}$ filters are held flat by a steel hold-down plate of the same outside dimensions with an opening $18 \times 23 \mathrm{~cm}$ to match the effective filtration area of the high-volume sampler. Additional details of construction can be obtained from the manulacturer's instruction manual. Membrane filters with a diameter of $10.0 \mathrm{~cm}$ can also be counted by centering them on the stecl planchet.

The counting gas .s P-10 (90\% $\mathrm{Ar}$ and $\left.10 \% \mathrm{CH}_{4}\right)$ used without further purilication from a commercial cylinder through a two-stage regulator. From the regulator mounted on the gas eylinder, the P-10 gas thows through a small gas shut-off valve that controls flow rate and then through a (0.45- $\mu \mathrm{m}$ Acro-50 filter disk to filter any large-size particulate material present in the gas stream that would gradually increase the contamination and background of the chamber.

Soil samples are initially dried and sieved to remove root mat, rocks, and other debris. A 100) my sample of the soil is then ground using a pestle and mortar with $30 \%$ ethanol, and following grinding, the liquid containing the finely-divided suspended material is removed from the mortar and placed in the glass tube of a small sprayer. The process is repeated twice to recover as much of the material as possible. The suspension is then shaken and sprayed with occasional additional shaking 


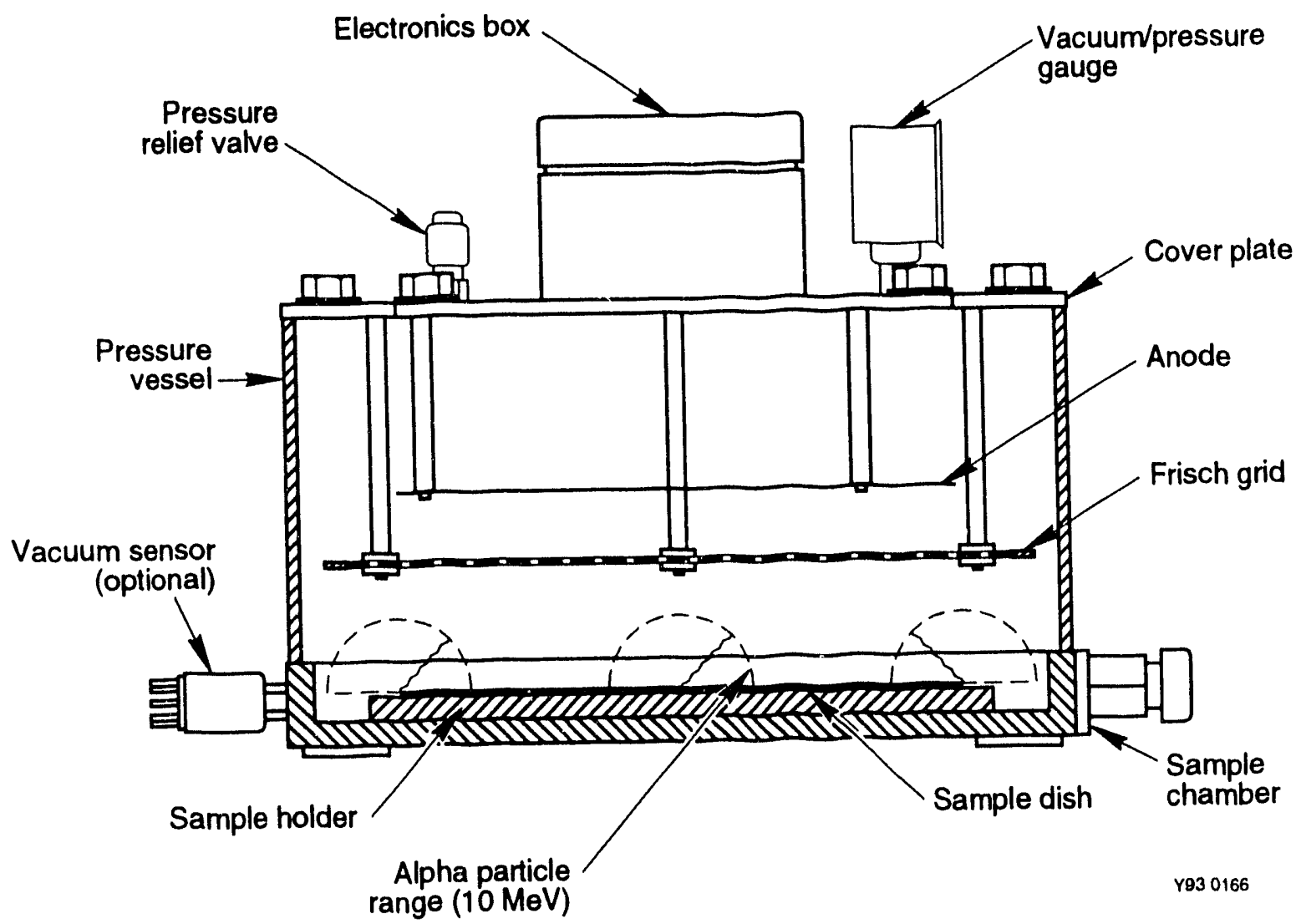

Figure 3. Cut-away view of Ordela large-area ionization chamber. 
onto the 25-cm stainless steel sample pan as uniformly as possible. The simple pan is then dried under an infrared lamp.

High-volume air sampler membrane filters and large-area smear fillers require no sample preparation. The filter is simply placed in the filter holder in the ionization chamber and is secured by the appropriate hold-down plate.

\subsubsection{X-ray/Gamma-ray Spectrometer}

The $x$-ray/gamma-ray spectrometer determines the presence of plutenium in soils, smears, and lilters by eounting uranium $L x$-rays produced by the alpha decay of plutonium radioisotopes. These $\mathrm{x}$-rays, which are lower in energy (longer wavelength) than the $\mathrm{Kx}$-rays, are olten emitted following alpha decay. It is possible to measure the presence and quantity of many radionuclides such as plutonium and americium radionuclides by measuring the number of emitted $L x$-rays per unit time. This is the principle upon which the $\mathrm{L} x$-ray spectrometer operates. The technique involves accumulating both $x$-rays and gamma rays in one spectrum in one count so that the spectrometer can simultaneously measure concentrations of alpha and gamma-ray emitting radioisotopes.

The spectrometer consists of a $60 \mathrm{~mm}$ diameter, thin-window, $\mathrm{n}$-type germanium detector capable of efliciently measuring $x$-rays and gamma rays. The gain is chosen 10 cover energies from about $10 \mathrm{keV}$ to about $1,350 \mathrm{keV}$ with an 8,192-channel analyzer. Under these conditions, the germanium spectrometer can measure simultaneously the presence of plutonium, ${ }^{241} \mathrm{Am}$, and radioisotopes that emit gamma rays having energies below $:, 350 \mathrm{kev}\left(\mathrm{e} \cdot \mathrm{g} .{ }^{60}{ }^{60} \mathrm{Co}\right.$ and ${ }^{137} \mathrm{Cs}$ ). The detector is equipped with a 30-L liquid nitrogen dewar, dual encrgy pulser, ${ }^{18}$ and automatic sample changer capable of processing 100 samples wituout the need for operator intervention. The pulser injects pulses into the test input of the resistive feedback preamplifier as shown in Figure 4. These pulses are processed through the preamplifier, linear amplifier, pile-up rejector, and analog to digital converter $(A D C)$ the same way that photon pulses are processed except that, before storage, the pulser pulses are digitally offset after being eonverted to digital format so that in the multichannel analyzer (MCA) spectrum pulser pulses are separated from photon events. The pulser data are stored with each spectrum and subsequently used during spectrum analysis to determine the energy calibration of the spectrum, coeflicients of the peak-width function, and dead time during spectrum accumulation.

Soil samples are prepared in the same way that bulk soil samples are prepared for analysis using the large-area ionization chambers. The bulk soil sample is dried and then sieved fo reduce the maximum particle size 10 less than 50 mesh $(<300 \mu \mathrm{m})$. A thin plastic container having a $65 \mathrm{~mm}$ inside diameter and $3 \mathrm{~mm}$ depth is placed on the weighing pan of an analyticial balance, and its tare weight is determined. Ten grams of the minus 50 mesh soil is loaded into the sample containcr while the container is on the weighing pan of the balance. When the sample cortainer contains $10 \mathrm{~g}$ of soil. the container lid is pressed onto the lower hall of the container and the container is shaken from side to side to distribute the soil evenly.

The $x$-ray portion of each spectrum is analyzed by a linear least-squares spectral fitting technique originally developed for the analysis of spectra from $\mathrm{NaI}(\mathrm{TI})$ deteciors. The $\mathrm{x}$-ray spectrum analysis 


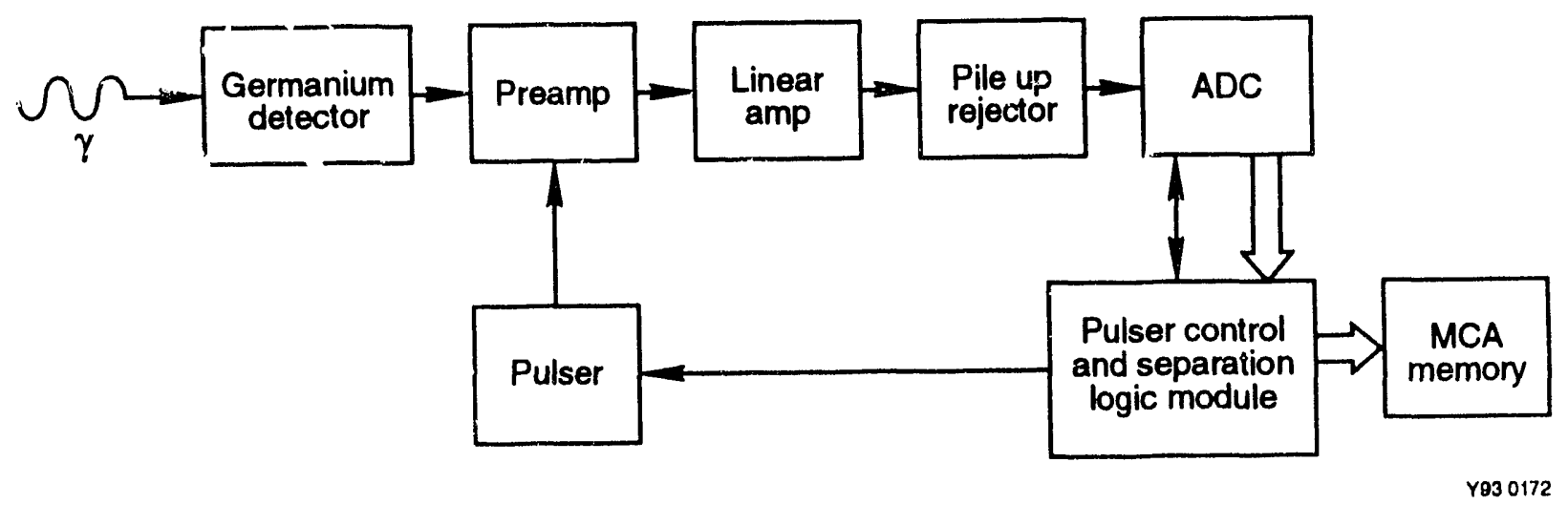

Figure 4. Block diagram of x-ray/gamma-ray spectrometer electronics. 
code, LXRAY," was developed and tailored for use with the $x$-ray/gamma-ray spectrometer. The gamma-ray portion of each spectrum is analyzed using VAXGAP, ${ }^{19,21}$ the gamma-ray spectrum analysis code that has been in routine use at the INEL for a number of years. The integration of LXRA Y as a subroutine of VAXGAP has been completed.

\subsubsection{Alpha Continuous Air Monitor}

The alpha CAM selected for use, the ANL-W alpha CAM, ${ }^{c, 21,22}$ is equipped with a (wo)-stage virtual impactor to climinate radon progeny and concentrate airborne plutonium-bearing particulates. Air, which is sampled at the relatively high rate of $280 \mathrm{~L} / \mathrm{min}\left(10 \mathrm{ft}^{3} / \mathrm{min}\right)$, is drawn through a circular array of inlet jets and directed towards a complementary array of receiving tubes. A major portion of the air leaving the jets $(200 \mathrm{~L} / \mathrm{min})$ is drawn off laterally before the airstream enters the receiving tubes. Small particles entering the inlet jets follow the lateral flow of air and do not enter the receiving tubes. Large particles not able to follow the lateral airflow enter the receiving tubes. This arrangement is repeated in a second stage in the impactor, with the lateral flow in this stage being $58 \mathrm{~L} / \mathrm{min}$. In principle, the minor $(20 \mathrm{~L} / \mathrm{min}$ ) airflow exiting the second sel of receiving tubes contains most of the plutonium-bearing particulates that entered the impactor. This minor airllow is directed to a sample collection filter spaced about $3 \mathrm{~mm}$ from a 90()$-\mathrm{mm}^{2}$ solit-state silicon detector.

Each alpha CAM consist: of an AivL-W type air sampling head, 90()- $\mathrm{mm}^{2}$ solid-state silicon detector, detector bias supply, preamplifier, linear amplifier, ADC, multiplexer, and AIM. As shown in Figures 5 and 6, the CAM sampling head, silicon detector, preamplifier, air sampling pumps, and mass flow sensors are housed in one cabinet, and the detector bias supply, lincar amplifier, ADC, multiplexer, and AIM are housed in a separate electronics cabinet. As shown in Figure 6, the electronics for two CAMs are housed in one electronics cabinet. Thus, for the case of four CAMs, four CAM sampling cahinets and two electronics cabinets will be installed inside the pit enclosure tent. For each CAM, the major and minor air flows through the CAM are continuously monitored using two mass flow sensors. The voltage output of each mass flow sensor is input into a multiplexer so that the flow data can be stored along with the spectral data being stored in the AIM. Both flow rates are displayed and routinely updated in the corresponding spectrum display window on the alpha CAM X-terminal monitor located inside the RTML analysis trailer. Because the preamplifiers are temperature sensitive and temperatures inside the pit enclosure tent are expected to vary diurnally, each CAM cabinet is equipped with a heater/air conditioner. Each electronics cabinet is equipped with an air conditioner to compensate for the heat generated by the ADCs and AIMs.

Of the spectrum analysis methods that have been developed, the most commonly used are those that determine net counts in the ${ }^{239} \mathrm{Pu}$ peak by subtracting from the total counts in the ${ }^{239} \mathrm{Pu}$ peak some fraction of the counts in adjacent regions of the spectrum. In each casc, the expression for net ${ }^{239} \mathrm{Pu}$ counts is a linear function of counts in the ${ }^{239} \mathrm{Pu}$ and background regions of the spectrum. Three such spectrum analysis algorithms, which are currently installed in the majority of eommercial alpha CAMs, were evaluated during FY-91 and FY-92. The results showed that the coefficients used

b. M. H. Putnam, An Operator's Guide to LXRAY, unpublished, March 1993.

c. J. M. Larson and D. L. Hall, ZPPR Plutonium Monitor, ZPR-I Mcmo No. 389, Ficbruary 1976. 


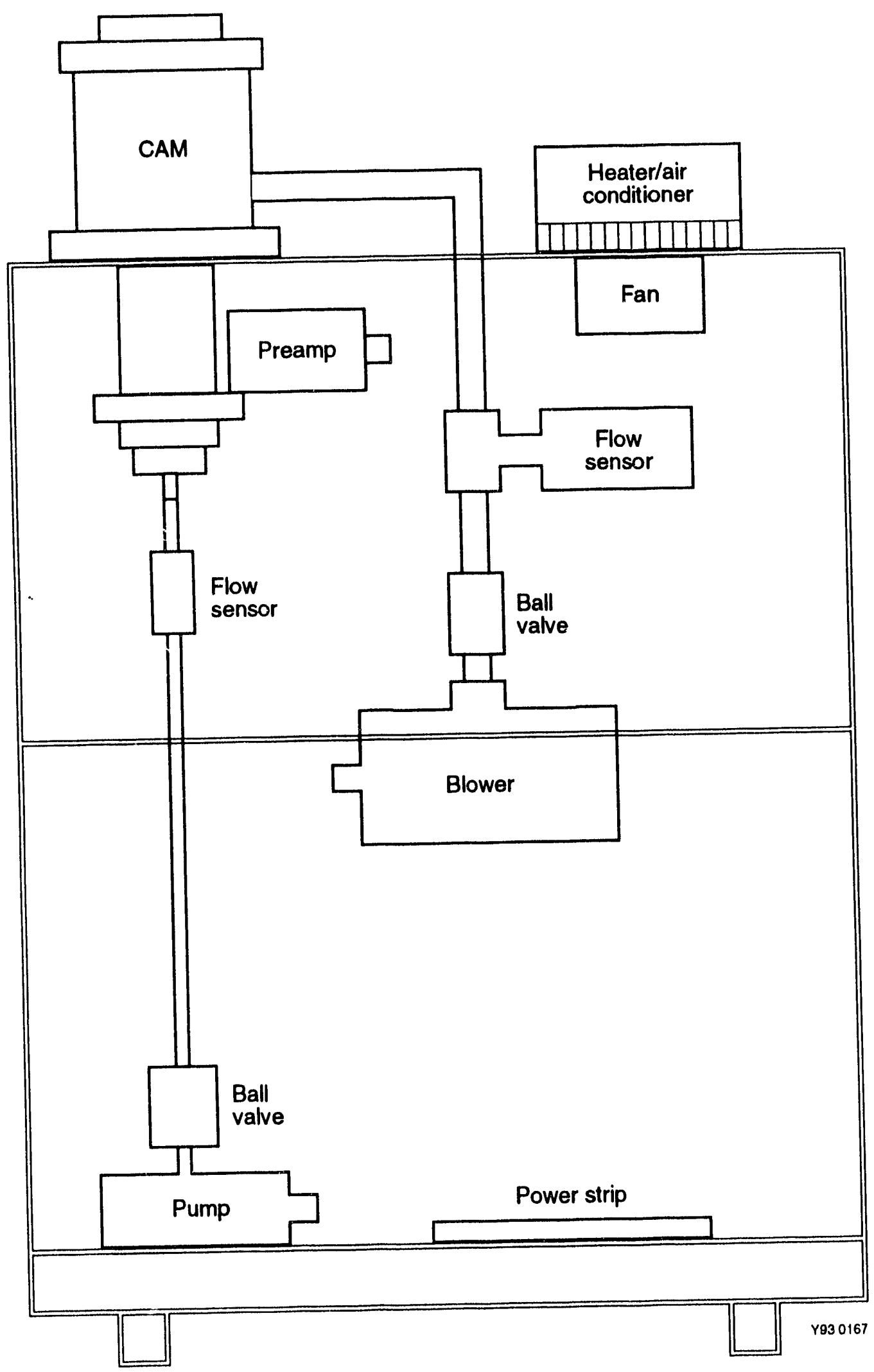

Figure 5. Diagram of alpha CAM sampling cabinet. 
From CAM \#1

From CAM \#2

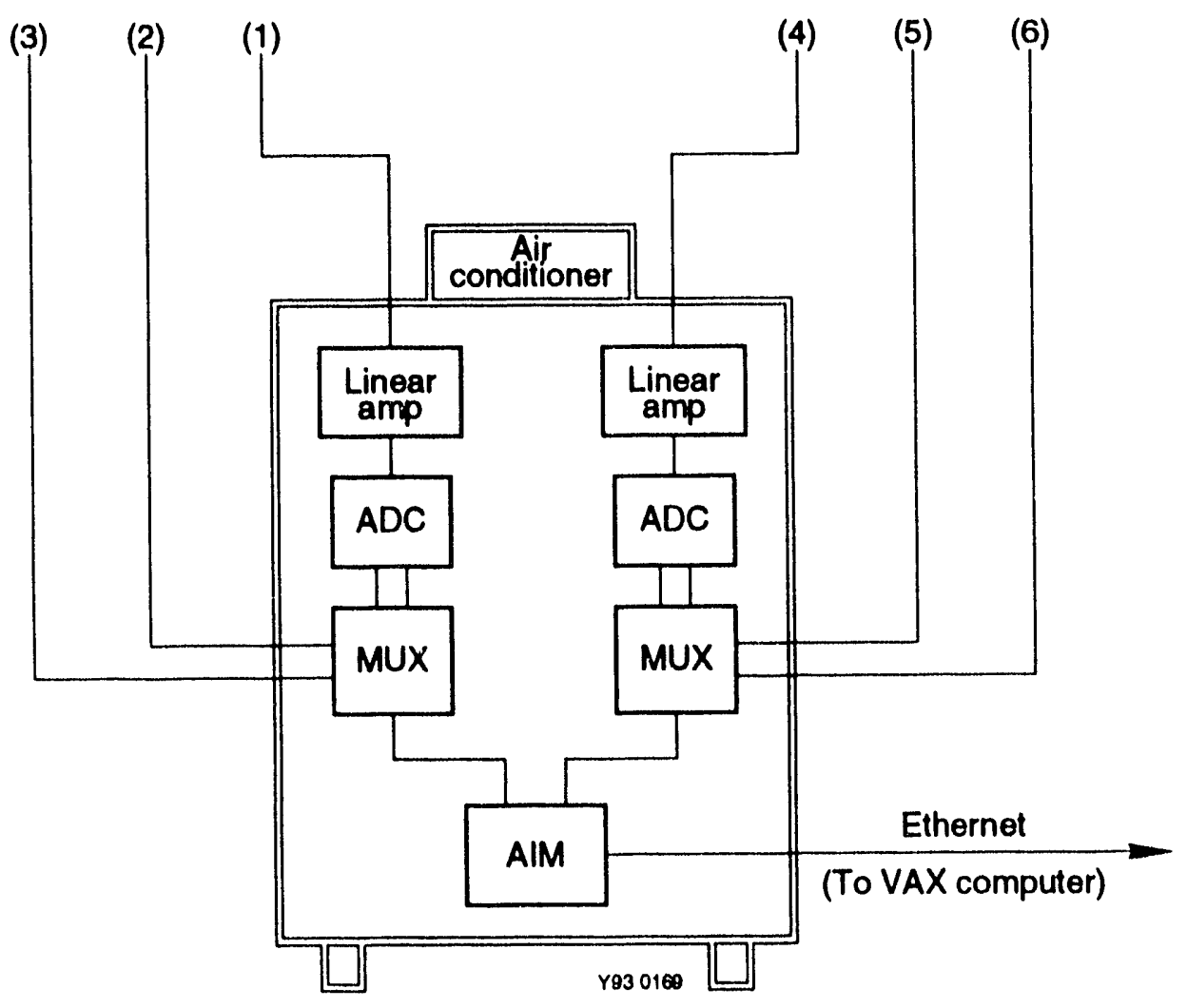

Figure 6. Block diagram of the alpha CAM electronics cabinet. 
for background subtraction are strongly dependent on the concentration of dust in the air being sampled and also vary as a function of sampling time.

Methods were identified that might allow calculating background coefficients during air sampling using parameters of the background alpha peaks. However, these methods have not yet been adequately tested. Alpha spcetrum peak fitting codes have recently become available (e.g., the GENEA code developed at Westinghouse Hanford and the ALPHAMAT code now available from EG\&G ORTEC) that might circumvent these problems. Both codes fit a Gaussian function to the high-energy portion of the alpha peak and a quadratic tail to the low-energy portion of the peak. The fitting is an iterative stripping technique, starting at the highest energy peak and moving downward, peak by peak. The GENEA alpha spectrum analysis code was recently installed on the VAX computer located in the Radiation Measurements Laboratory (RML) at the Test Reactor Area and was evaluated experimentally for use in analyzing spectra collected using the ANL-W alpha CAMs. To date, the results obtained using the GENEA code have not been satisfactory.

A two-window spectrum analysis algorithm that was previously tested with the ANL-W CAM will be used to analyze alpha CAM spectra collected during the demonstration. The algorithm determines net counts in the ${ }^{239} \mathrm{Pu}$ peak by subtracting from the total counts in the ${ }^{239} \mathrm{Pu}$ peak some fraction of the counts in an adjacent background region of the spectrum. These regions, or encrgy windows, are commonly referred to as regions of interest (ROIs). The algorithm employs one ROI that encompasses the energy region of the ${ }^{239} \mathrm{Pu}$ peak and one background ROI. The background ROI used in the two-window algorithm is located just above the ${ }^{239} \mathrm{Pu} \mathrm{ROI}$ and encompasses the low-energy tail of the $6.00 \mathrm{MeV}{ }^{218} \mathrm{Po} /{ }^{212} \mathrm{Bi}$ alpha peak. The number of net counts in the ${ }^{239} \mathrm{Pu}$ peak is expressed as a simple linear equation involving a single coefficient whose value must be determined experimentally. The value of the coefficient determines what fraction of the counts in the background ROI must be subtracted from the counts in the ${ }^{239} \mathrm{Pu}$ ROI to yield zero net counts in the absence of ${ }^{239} \mathrm{Pu}$. The equation for net counts in the ${ }^{239} \mathrm{Pu} \mathrm{ROI}$ is

$\mathrm{C}_{\mathrm{Pu}}=\mathrm{C}_{\mathrm{i}}-\mathrm{kC}_{2}$

where

$\mathrm{C}_{1}=$ total number of counts in the ${ }^{239} \mathrm{Pu}$ ROI (counts)

$\mathrm{C}_{2}=$ total number of counts in the background ROI (counts)

$\mathrm{k}=\mathrm{a}$ proportionality constant whose value must be determined experimentally. 


\section{TEST PROCEDURES}

The test procedures discussed in this section include how the samples will be collected, prepared, counted, and analy ed during the remote excavation demonstration at the INEL's RWMC Cold Test Pit. During actua, wot retrieval in a TRU pit or trench, samples collection would be more closely related to the actual retricval operation. For example during the Cold Test Pit retrieval, samples will be collected near the actual excavation but not in the actual pit because of salety reasons (interference with the remotely controlled excavation). During hot operation, many samples would be remotely collected directly from the pit.

\subsection{Preparation}

The RTML sample preparation trailer, analysis trailer, and $6.5,30$, and $50 \mathrm{~kW}$ diesel generators will be moved to a location adjacent to the Cold Test Pit. The two trailers will be parked next to one another, preferably with the personnel doors facing one another to minimize the distance between them. The HEPA filter, exhaust fan, and duct-work for the Class A hood in the sample preparation trailer, which are mounted on a platform, will be installed on the roof of the sample preparation trailer after arrival at the Cold Test Pit. A small crane will be used to hoist the platform to the roof of the sample preparation trailer. Four support poles, one for each corner of the platform, will be installed to help support the weight of the platform.

The four alpha CAM sampling stations and two associated CAM electronics cabinets will be installed inside the Cold Test Pit enclosure tent. Power to the six alpha CAM cabinets will be supplied from the $6.5 \mathrm{~kW}$ diesel generator. A thin-wire Ethernet cable will connect the two CAM electronics cabinets to the VAX computer installed in the RTML analysis trailer. To make the connection to the VAX computer, the Ethernet cable will pass through a penctration in the wall of the RTML analysis trailer.

The x-ray/gamma-ray spectrometer and its shield will be installed in the sample changer cabinet after the RTML analysis laboratory is moved to the Cold Test Pit. The x-ray/gamma-ray spectrometer's dewar will be filled with liquid nitrogen before the start of measurements and filled with liquid nitrogen at least once per week during the demonstration. The dewar will be filled either by connecting a portable liquid nitrogen tank to the fill line mounted on the outside wall of the analysis trailer or by pouring liquid nitrogen into the fill-port on the neck of the dewar using a small hand-held liquid nitrogen container.

\subsection{Precautions}

Procedures governing the handling of radioactive materials, liquid nitrogen, and performance of laboratory activities are provided in the EG\&G Idaho Company Procedures Manual and in the procedures manual being developed for this test and will be adhered 10 during the field test demonstration. The sample preparation, counting, and analysis activities will be covered by the Radiation Work Permit. 


\subsection{Test Operations}

Procedures for collecting, preparing, and analyzing samples are described in this section.

\subsubsection{Sample Collection}

Nonradioactive soil samples will be selected from the vicinity of the Cold Test Pit. Representative sampling of an area is not applicable for this test because none of the sampled soil is radioactive. However, the following protocol is recommended to reduce inclusion of extrancous material in the soil brought to the sample preparation trailer for drying and sieving. Before starting the retrieval demonstration, several hundred soil, filter, and smear samples will be collected from the area under the tent enclosure. These samples will be catalogued in the logbook by the location and time obtained and assigned a number. The samples will be prepared for the counting laboratory so when the actual retricval demonstration starts, the counting laboratory can process the samples. During the demonstration, up to 20 samples of soil filters and smears will be obtained from each catalogued box of pit debris that comes out of the tent enclosure. Additionally, up to 20 samples will be obtained from within the tent enclosure during each box (dumpster) changeout.

5.3.1.1 Soil. The soil selected for sampling will be as free as possible from root mat, stones, twigs, or other debris by using a small garden hand trowel to ensure that the finest material is collected. At least live separate scoops will be taken from each area to obtain a representative sample and placed in a 1-quart heavy-duty polyethylene bag with a friction closure and write-on area. Each bag will be filled about haif full without interlering with closure of the bag or unduly contaminating the outside of the bag, and the bag will be marked with a two-digit identilication number and the date and time of collection. This descriptive information, which is necessary to identify the location where the sample was collected, will be recorded in a sample logbook for permanent reference. The sample will then be surveyed with alpha and gamma survey instruments to ensure that the outside of the sample bag is not contaminated before sending it to the RTML sample preparation laboratory.

5.3.1.2 Airborne Dust. Samples of airborne dust to be analyzed by large-area ionization chamber alpha spectrometry will be collected on $20 \times 24-\mathrm{cm}$ lluoropore membrane lilters with 1.0 $\mu \mathrm{m}$ pores for 10 minutes at about $420 \mathrm{~L} / \mathrm{min}$, or longer if desirable, using a high-volume sampler. Each filter will be placed in a suitable polyethylene bag, and the bay marked with a two-digit identification number, date and time sampling commenced, date and time sampling was terminated, and average flow rate during sampling. This descriptive information, which is necessary to identify the location where the sample was collected, will be recorded in a sample logbook for permanent reference.

Samples of airborne dust for analysis by $\mathrm{x}$-ray/gamma-ray spectrometry will be collected on $47 \mathrm{~mm}$ diameter filters installed in the four alpha CAMs. The particular filters installed in the alpha C.AMs will be Millipore $47 \mathrm{~mm}$ diameter fluoropore filters having $1.0 \mu \mathrm{m}$ pore size. In each case, the filter will be placed in a lilter holder that will be secured to the CAM virtual impactor before the start of sampling. For each CAM, the initial sampling flow rate will be $280 \mathrm{~L} / \mathrm{min}$. Following its removal from the filter holder, each CAM filter will be placed in a suitable polyethylene bag and the bag marked with an identification number, date and time sampling was initiated, and date and time 
sampling was terminated. This descriptive information, which is necessiry to identily the location where the sample was collected, will be recorded in a sample logbook for permancent reference.

5.3.1.3 Smears. Up to 10 smears of surface contamination lakcon lor analysis by x-ray/gamma-ray spectrometry will be collected on $47 \mathrm{~mm}$ diameter filters. Each smeall will be placed directly in a plastic sample container normally used with the $x$-ray/gammatray spectrometer to minimize handling of the smear, and the container will be marked with a two-digit identification number and date and time of sampling. Samples of surface dust collecled for analysis with the large-area ionization chamber alpha spectrometers will be collected with a $20 \times 25-\mathrm{cm}$ fluoropore membrane filter wrapped around a paint roller or with a vacuum hose altached 10 a high-volume sampler equipped with a $20 \times 25-\mathrm{cm}$ lluoropore membrane filter. In each ease, the sample identification number and descriptive information needed to identify the surlace smeared will be recorded in a sample logbook for permanent reference.

\subsubsection{Sample Pretreatment}

The soil sample in the 1-quart polyethylene bag is emptied into a disposable aluminum pan, approximatcly 6-1/2 $\times 9 \times 1-1 / 4$ in. (Reynolds Metals Co., Richmond, Virginia, No. RC 576). Any root mat, twigs, stones, or other obvious debris is removed and discarded into a waste container. The pan is placed in a drying oven at $190^{\circ} \mathrm{C}$ until the sample is dry, then removed and allowed to cool in air to room temperature. Any large clods are broken up with a poreclain pestle, taking care not to penetrate the botlom of the pan. The entire sample is poured into a 5()-mesh, 300$) \mu \mathrm{m}$ stainless-stecl standard testing sieve, 8 -in. outside diameter $\times 2$ in. deep (Fisher Scientific, Piltshurgh, Pennsylvania, No. ()4-881-10T), and shaken rapidly horizontally until at least $50 \mathrm{~g}$ of minus 50 mesh matcrial has been collected in the bottom pan. Enough of this material is then transferred with a long, thin scoop) 10 a 2-02 polypropylene wide-mouth bottle (Fisher Scientific, Pittsburgh, Pennsylvania, No. 02-893 BB) to fill the bottle ahout half full, about $50 \mathrm{~g}$. The bottle is shaken vigorously for a few seconds to homogenize the contents, is marked witis the same identification number that was on the original polyethylene bag, and is placed in order in a 20 -bottle carrier tray.

\subsubsection{Sample Preparation for Counting}

5.3.3.1 Large-area Ionization Chamber Alpha Spectrometry. A 10() -mg sample of the prepared soil is ground thoroughly with four consecutive $2-\mathrm{mL}$ portions of $30 \%$ ethanol in a diamonite mortar for about 1 minute each. After each grinding, the mortar is tipped slightly to allow the ethanol containing material linely divided enough to remain suspended to run off the heavier material. The licyuid suspension is then litted out immediately with a suction-type pipel and placed in the reservoir of the glass sprayer. The residue remaining after the third grinding is suspended in the last portion as well as possible and added to the sprayer. The suspension is then shaken and sprayed with frequent additional shaking onto the $25 \mathrm{~cm}$ diameter stainless-sleel sample pan as uniformly as possible. The pan is heated with an infrared lamp during spraying and then thoroughly dried after spraying is completed. The dried sample is inserted into the ionization chamber and counted.

No special preparation is necessary for counting smears or filiers used to collect dust samples. The membrane filler is placed in the ionization chamber, held that by the hold-down frame, and counted. 
5.3.3.2 X-ray/Gamma-ray Spectrometry. The bottom portion of the thin plastic sample container used with the $x$-ray/gamma-ray spectrometer is placed on the analytical balance, and its tare weight is measured. Ten grams of minus 50 mesh prepared soil is poured into the sample container. The mass of soil added to the sample container is recorded to the nearest milligram. The container is then removed from the balance and placed on a solid surface and the container lid is pressed onto the lower half of the container. The container is shaken from side 10 side 10 distribute the soil evenly. The sealed sample container is placed in the sample magazine of the x-ray/gamma-ray spectrometer sample changer for counting.

\subsubsection{Sample Analysis}

The large-area ionization chamber will operate on an 8-hour/day basis, and determinations of throughput will be extrapolated to longer shifts by using the two available ionization chambers. The U-L-Shell $x$-ray system will process samples in a semibatch mode during the 8-hour shilt. For the following two shifts, 100) samples will be loaded for a 16-hour count. This long, overnight count will be repeated at least twice during the demonstration. The alpha CAMS will be run on a variety of shifts, including four 8-hour shifts and overnight depending on dust loadings.

5.3.4.1 Large-area Ionization Chamber Alpha Spectrometry. The gas and vacuum connections to the ionization chamber are shown in Figure 7. V-1, V-2, and V-3 are three-way gas valves with a closed position in the center. V-2 permits direct venting of the gases to the atmosphere during flushing to avoid gradual contamination of the chamber that would occur if the excess gas was allowed to exit through the access port.

At least once a day immediately before first use, V-2 is opened to the atmosphere and P-10 gas is allowed to come through V-3 just long enough to refill the lines and filter back to the eylinder with fresh, oxygen-free P-10. The sample holder containing a sample pan or filter is placed into the ionization chamber, the door of the acess port is closed and dogged lightly against the rubber "O"-ring. $\mathrm{V}-1$ is then opened to the vacuum pump for at least 1 minute after no further movement of the gauge needle is detected. The Leybold-Heraus pump requires about 1-1/2 minutes to evacuate the chamber to the limit of the vacuum gauge, so a total of at least 3 minutes is allowed 10 ensure adequate removal of air. V-3 is then opened to the P-10 line, V-2 to V-1, and V-1 to the ionization chamber. The lower stage of the P-10 regulator is set at about $110 \mathrm{kPa}$ so that the gas can be admitted rapidly to minimize loss of time but not so rapidly as to blow the sample around or to permit significant overpressure to occur accidentally. When the gauge indicates a gas pressure of $100 \mathrm{kPa}$ above atmospheric pressure, $\mathrm{V}-1$ is closed. A voltage of $2,750 \mathrm{~V}$ is applied to the ionization chamber anode, and spectrum accumulation is initiated.

Following completion of the 10 minute count, the high voltage is reduced to zero to avoid pessible damage to the grid when the chamber is next evacuated. $V-1$ is opened to the vacuum pump until the pressure gauge indicates zero at which time V-1 is closed to stop evacuation, the sliding access drawer is opened, and the sample is removed. The entire alpha spectrum is stored in the VAX $40(0)$ memory and analyzed using a ROI spectrum analysis algorithm. Analysis results are printed using a laser printei When not in use, the ionization chambers are kept in an atmosphere of P-10 gas to prevent absorption of oxygen and nitrogen by the internal surfaces of the chamber. 


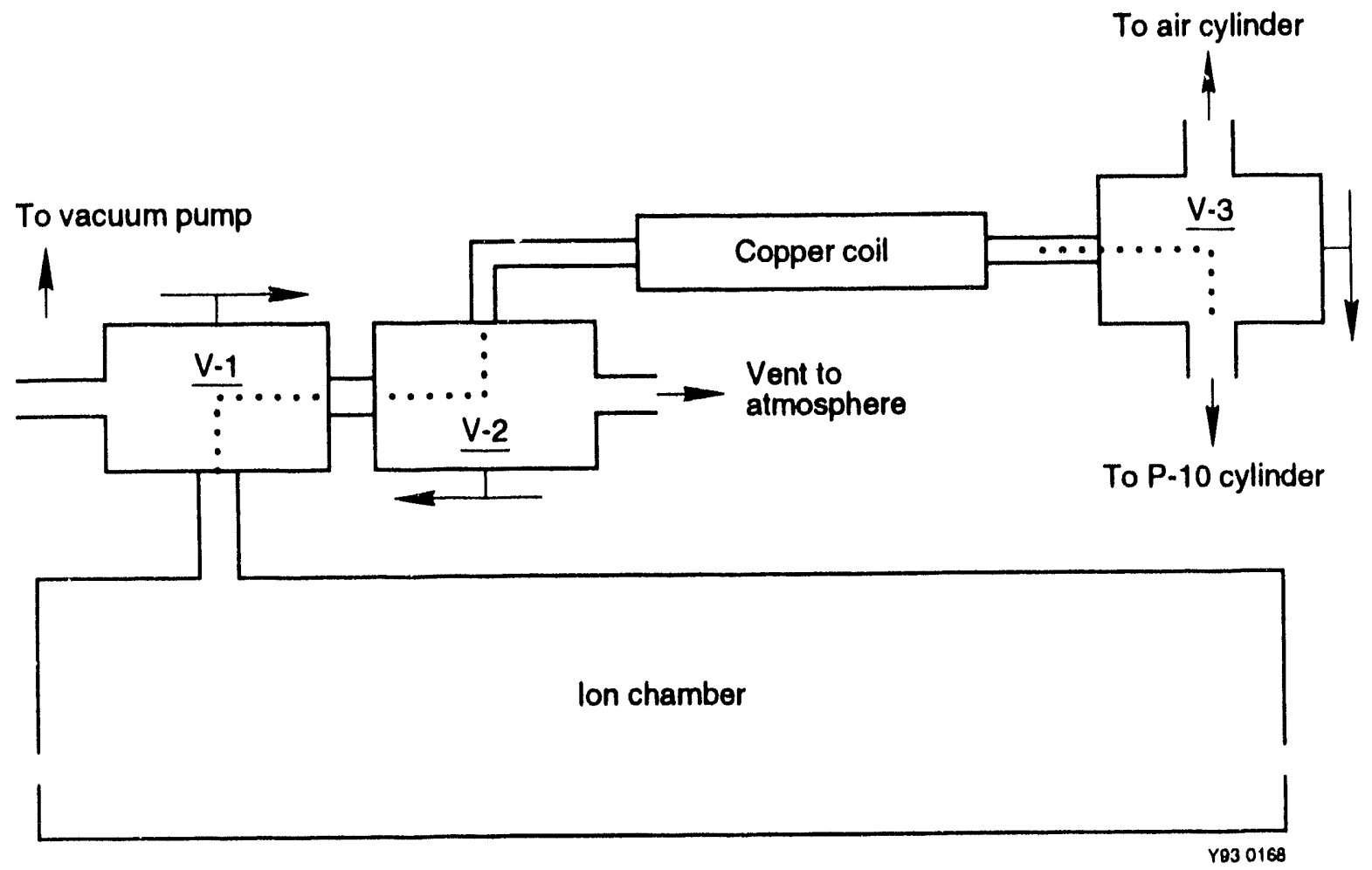

Figure 7. Ionization chamber gas and vacuum connections. 
5.3.4.2 X-ray/Gamma-ray Spectrometry. Prepared samples are loaded into the magazines of the spectrometer's sample changer. As currently configured, the sample changer can aceommodate 100 samples. Before counting is initiated, a count que is construeted using the XGAP program. For each of the samples to be counted, a sample identification number, sample description, and count time are entered into a counting que. Automatic analysis of a set of samples is started by entering the command "GOQ" on the $x$-ray/gamma-ray spectrometer's X-terminal. Samples are analyzed sequentially beginning with the sample located in the position having the lowest position number. After each sample is counted, the XGAP program automatically analyzes the x-ray/gamma-ray spectrum and prints the results using the laser printer. Gamma-ray results are printed first, followed by the $x$-ray results.

5.3.4.3 Alpha Continuous Air Monitor. The continuous air monitoring system eonsists of four air sampling cabinets and two electronics cabincts. As shown in Figure 2, each electronics cabinct serves two air sampling cabinets. Each of the air sampling cabinets is equipped with an ANL-W two-stage virtual impactor, 900)- $\mathrm{mm}^{2}$ solid-state silicon detector, filter holder, pumps for pulling air through the impactor and sampling filter, and thow sensors for monitoring air llow during sampling.

Before operation, a Millipore $47 \mathrm{~mm}$ diameter Fluoropore filter having a pore size of $1.0 \mu \mathrm{m}$ must be installed in the CAM filter holder. Access to the filter holder is achieved through the rear door of the air sampling cabinet. A switch mounted to an internal shelf automatically shuts ofl the detector bias voltage when the rear cabinet door is opened. The filter holder, which is located at the bottom of the virtual impactor, is removed from the impactor body by turning it one-half turn counter-clockwise. Using tweezers, the $47 \mathrm{~mm}$ diameter filter is placed over the fine-mesh screen in the filter holder and centered. Once the filter is centered, the air sampling pumps are turned on to hold the filter in place during the installation of the filter holder. The air sampling pumps are turned on with the power switch located in the upper right hand corner of the rear frame of the cabinct. The filter holder is secured to the impactor body by inserting it into the filter holder receptacle at the bottom of the impactor body and turning it clockwise one-half turn.

Using the alpha CAM X-terminal located in the RTML analysis trailer, spectrum accumulation is initiated using the ACAM program by entering the command "START," desired counting time in seconds, and depressing the "RETURN" key. When spectrum accumulation is started, lie spectrum for the CAM will be displayed in the spectrum display window on the CAM X-terminal monitor corresponding to the CAM. The impactor exhaust and filter eflluent air llow rates for each CAM will be displayed below the corresponding alpha spectrum.

Following the completion of a sampling cycle, the filter is removed from the filter holder using the following procedure. The filter holder is removed from the impactor body by turning it one-hall turn counter-clockwise. This operation is performed with the air sampling pumps running so that the lilter remains with the filter holder during removal. When the filter holder is disengaged, the air sampling pumps are turned off. The filter is transferred from the filter holder to a 2 in. diameter petri dish, and a new filter is installed using the procedure previously described. 


\subsection{Data Analysis}

The measurement of the activities of radionuclides in soils requires that the mass of sample analyzed be known. In the case of soil samples prepared for analysis using the $x$-ray/gamma-ray spectrometer, the bottom portion of the thin plastic sample container will be placed on the balance pan and the tare weight measured before soil is added to the container. Ten grams of minus 5()-mesh soil will then be added to each container. The mass of soil will be recorded to the nearest milligram. In the case of samples prepared for the large-area ionization chamber alpha spectrometer, the mass of sample removed for grinding using the pestle and mortar will remain fixed at $10(0) \mathrm{mg}$. The quantity of soil removed for grinding will be recorded to the nearest tenth of a milligram. Some losses are expected during the suspension and spraying of the soil onto the sample pan used for eounting. Additional experimental work is required to quantify the losses accurately.

Alpha and $x$-ray/gamma-ray spectra will be analyzed using software programs installed on the VAX 4000) model 100 eomputer. Photon spectra collected using the $x$-ray/gamma-ray spectrometer will be analyzed automatically using the program XGAP, which is a combination of the LXRAY and VAXGAP programs that analyze, respectively, the x-ray and gamma-ray regions of each spectrum. Alpha spectra collected using the four alpha CAMs and two ionization chambers will be analyzed automatically using the ACAM and ION programs, respectively. Both programs analyze alpha spectra by means of ROI-type analysis algorithms.

The methodology of Currie ${ }^{23}$ is being used to calculate the sensitivities of the analytical measurements. His equation for paired observations of sample and background with a probability of 0.05 that activity will be detected when nc.te is present or that activity will not be detected when in lact it is present is

$$
\text { LLD }=2.71+4.66 \mathrm{~B}^{1 / 2}
$$

In terms of concentration in soil, expressed as $\mathrm{pCi} / \mathrm{g}$, the equation becomes

$$
\text { LLD }=\frac{2.71+4.66 \mathrm{~B}^{1 / 2}}{2.22 \cdot \mathrm{T} \cdot \epsilon \cdot \mathrm{Y} \cdot \mathrm{M}}
$$

where

$$
\begin{aligned}
& \mathrm{B}=\text { total number of hackground counts in the region of interest (counts) } \\
& 2.22=\text { number of disintegrations per minute per pCi } \\
& \mathrm{T}=\text { counting time (minutes) }
\end{aligned}
$$


$\epsilon \quad=$ absolute counting efficiency (counts per disintegration)

$\mathrm{Y}=$ fractional recovery in the region of interest

$\mathrm{M}=$ mass of samplc (g). 


\section{SAMPLE CONTROL AND DOCUMENT MANAGEMENT}

During the demonstration, laboratory notebooks will be maintained for the large-area ionization chamber alpha spectrometer, $x$-ray/gamma-ray spectrometer, alpha CAMs, and VAX 4000) model 100) computer. Instrument calibration results for each measurement system will be documented in the project file or instrument logbook. Any changes made to settings or maintenance performed will be noted in the laboratory notcbook assigned to the system.

Sample identification numbers and descriptions will be entered in a sample logbook. The sample logbook will be taken into the fïeld by personnel collecting samples. Following the collection of each sample, personnel collecting the sample will enter into the sample logbook: (a) two-digit sample identification number, (b) date and time of sampling, (c) sampling location, and (d) description of the sample. The date and time of sampling and sample identilication number will also be written on the sample eontainer. 


\section{EQUIPMENT}

Samples collected from the Cold Test Pit will be prepared for analysis in the RTML sample preparation trailer and analyzed in the RTML analysis trailer. Electrical power for both trailers will be suppl: $\mathrm{d}$ from a $50 \mathrm{~kW}$ diesel generator. A VAX 4000 model 100 computer installed in the RTML analysis trailer witl analyze all spectral data. Two laser printers installed in the analysis trailer will be used to print hard copies of analysis results.

\subsection{Sample Collection}

- 1-quart polyethylene bag with friction closure

500 ea

- Indelible marking pen

6 ea

- Garden hand trowel

2 ea

- High-volume air sampler model HV-1SH

1 ea

: $\quad 20 \times 25-\mathrm{cm}$ fluoropore membrane filter

5 ea

- $\quad 21 \times 26-\mathrm{cm}$ polyethylene bag with friction closure

20 ea

- $\quad 47 \mathrm{~mm}$ diameter, Millipore cellulose acetate filter

$50 \mathrm{ca}$

- $47 \mathrm{~mm}$ diameter, Millipore fluoropore $1.0 \mu \mathrm{m}$ filter

50 ea

- 2 in. diameter petri dish

100 ea

\subsection{Sample Preparation}

- Sample preparation trailer with Class A hood

1 ea

- Aluminum sample pan

50 ea

- Gravity-llow drying oven

$1 \mathrm{ca}$

- Sieve assembly, 50 mesh

1 ea

- 2-oz polypropylene bottle

- Metler AE200 direct reading balance

$500 \mathrm{ca}$

- Pestle and mortar

1 ea

- Ethanol

1 ea

- Water

- 10-mL, all-glass air-operated sprayer

$1 \mathrm{qt}$

1 gal

1 ea

- $25 \mathrm{~cm}$ diameter stainless-steel pan

50 ea

- Infrared lamp

- $65 \mathrm{~mm}$ diameter $\times 3 \mathrm{~mm}$ deep plastic sample container

1 ea

- 4-gal polyethylene bu.ket

500 ea

1 ea

\subsection{Analytical Instruments}

\subsubsection{Large-area Ionization Chamber Spectrometer}

- Innization chamber with preamplifier (Ordela, Inc. models 8200A and 8210A) 2 ea

- Cylinder P-10 gas and two-stage regulator

- Cylinder compressed air and two-stage regulator

1 ea

- Vacuum pump

$1 \mathrm{ea}$

- High voltage bias supply

2 ea 
- Amplifier 2 ea

- ADC 2 ca

- Acquisition interface module 1 ea

- Nuclear instrument modulë (NIM) bin 2 ea

- X-terminal $1 \mathrm{ea}$

\subsubsection{X-ray/Gamma-ray Spectrometer}

- PGT NIGC 2830) thin-window, germanium detector with preamplifier and dual-energy pulser

- EG\&G ORTEC 30-L liquid nitrogen dewar

- Liquid nitrogen

- Gamma Products, Inc. G3200 gamma counting system

$30 \mathrm{~L}$

- Gamma Products, Inc. G6000 driver controller

$1 \mathrm{ca}$

- High voltage bias supply

- Amplifier

1 ea

- $\mathrm{ADC}$

1 ea

$1 \mathrm{ca}$

- AIM

$1 \mathrm{ea}$

- X-terminal

1 ea

- NIM bin

$1 \mathrm{ca}$

1 ea

\subsubsection{Alpha Continuous Air Monitor}

- Alpha CAMi air sampling cabinet

$4 \mathrm{ca}$
$1 \mathrm{ea}$
$1 \mathrm{ca}$
$1 \mathrm{ea}$
$1 \mathrm{ea}$
$1 \mathrm{ca}$
$1 \mathrm{ea}$
$1 \mathrm{ea}$
$1 \mathrm{ea}$
$50 \mathrm{ea}$
$50 \mathrm{ft}$

- Solid-state heater/air conditioner

- ANL-W two-stage virtual impactor

- Solid-state silicon detector

- Preamplifier

- $\quad 10 \mathrm{cfm}$ air pump

- $1 \mathrm{cfm}$ air pump

- High-volume flow sensor

- Low-volume flow sensor

- Fluoropore 47-mm filter

- 120 Vac extension cord

- Alpha CAM electronics cabinet

2 ea

- NIM bin

- High voltage bias supply

- Amplificr

- ADC

- Multiplexer

- AIM

- X-terminal

- $\quad 120$ Vac extension cord
$1 \mathrm{ca}$

$2 \mathrm{ca}$

2 ca

2 ea

$2 \mathrm{ca}$

1 ca

1 ca 100 lit 


\subsection{Maintenance and Operation}

RTML equipment will be maintained and operated according to RTML operating procedures. No preventive maintenance will be performed on RTML instruments during the demonstration. The dewar of the germanium spectrometer will be filled with liquid nitrogen twice a week while the RTML is at the RWMC.

\subsection{Calibration}

\subsubsection{Large-area Ionization Chamber Alpha Spectrometer}

Calibration standards containing three radionuclides having principal alpha energies as widely separated as possible are used to adjust the energy calibration and determine the linearity of response. The radionuclides used are ${ }^{230} \mathrm{Th},{ }^{239} \mathrm{Pu}$, and ${ }^{244} \mathrm{Cm}$ that emit alpha particles having average alpha energies of $4,684,5,155$, and $5,805 \mathrm{keV}$, respectively. The activity of each radionuclide is sufficient to give excellent counting statistics in a 10-minute count. The gain and digital offset will be maintained to keep the three alpha peaks in their desired channel positions. The analyzer has been set to cover 512 channels at $10 \mathrm{keV}$ per channel beginning at $2,800 \mathrm{keV}$ so that the alpha peak of the principal radon daughter ${ }^{214} \mathrm{Po}$ at $7,687 \mathrm{keV}$ is displayed at the higher energy end of the spectrum while providing as much space as possible at the lower energy end to accommodate degraded pulses.

\subsubsection{X-ray/Gamma-ray Spectrometer}

The following calibrations will be performed before the demonstration using the following procedures and programs. If instabilities or other unanticipated problems arise, the spectrometer will be recalibrated in the ficld.

The energy scale tor the entire energy region is determined from the pulser, which is calibrated against a special radioactive source comprised of ${ }^{57} \mathrm{Co},{ }^{137} \mathrm{Cs}$, and ${ }^{60} \mathrm{Co}$ using the XCALIB program. Since two different analysis programs are used to analyze the $\mathrm{L} x$-ray and gamma-ray energy regions of each spectrum, the spectrometer requires two separate and distinct radionuclide activity calibrations.

The spectrometer is calibrated for plutonium and ${ }^{241} \mathrm{Am}$ by counting standards containing known quantities of these radionuclides. The COMPONENT program subtracts the background from each component of the spectrum, corrects for the sample mass or volume, and scales each component to a fixed disintegration rate. When an unknown sample is analyzed, the $\mathrm{L} x$-ray portion of the spectrum is fit to the components of the calibration spectra using linear least squares methods. A standardization coefficient relates the relative magnitudes of the standard component with that of the unknown sample. The standardization coefficient is then scaled by the mass or volume of the sample and the count time to yield the sample activity or activity concentration.

With one exception, the gamma-ray energy region from about $59 \mathrm{keV}$ to $1,350 \mathrm{keV}$ is calibrated following the same procedure as is normally used for germanium gamma-ray detectors. A special mixed radionuclide calibration source is used that contains ${ }^{54} \mathrm{Mn}$ and ${ }^{65} \mathrm{Zn}$ in addition to ${ }^{241} \mathrm{Am},{ }^{109} \mathrm{Cd}$, 
${ }^{57} \mathrm{Co},{ }^{139} \mathrm{Ce},{ }^{203} \mathrm{Hg},{ }^{113} \mathrm{Sn},{ }^{137} \mathrm{Cs},{ }^{88} \mathrm{Y}$, and ${ }^{60} \mathrm{Co}$. This mix was chosen because most of the gamma rays emilled by this mix are relatively free of cascade coincidence summing. Since the gamma rays from ${ }^{88} \mathrm{Y}$ and ${ }^{60} \mathrm{Co}$ are in cascade, these gamma rays are not included in the efficiency measurements but can be used to estimate the amount of coincidence summing occurring with other radionuclides having gamma rays with energies above $800 \mathrm{keV}$. An efficiency curve from 50 to $1,400 \mathrm{keV}$ is developed using an efficiency measurement program EFF developed for use by the RML at the INEL.

\subsubsection{Alpha Continuous Air Monitor}

The energy calibration of each solid-state silicon detector is determined and intermittently checked by measuring a filter standard that contains ${ }^{230} \mathrm{Th},{ }^{239} \mathrm{Pu}$, and ${ }^{244} \mathrm{Cm}$. The three isotopes emit alpha particles having average energies of $4.684,5.155$, and $5.805 \mathrm{Mev}$, respectively. The absolute counting efficiency of each alpha detector is determined and checked by measuring cither the same filter standard used to perform energy calibrations or filter standards that contain known quantities of ${ }^{239} \mathrm{Pu}$. The latter standards were prepared using membrane filters having a pore size of $0.1 \mu \mathrm{m}$. The ${ }^{239} \mathrm{Pu}$ activity was transferred to the filters using a neodymium fluoride carrier in dilute perchloric acid. The method ${ }^{24}$ has been shown to provide an even distribution of activity over a filter surface with minimal loss of alpha particle energy. The quantity of material deposited on the filter standards is about $30 \mu \mathrm{g} / \mathrm{cm}^{2}$. 


\section{ANALYTICAL PROCEDURES}

\subsection{Instrumentation}

\subsubsection{Large-area Ionization Chamber Alpha Spectrometer}

Soil and filter samples are prepared for analysis following the procedures described in Sections 5.3.2 and 5.3.3.1 and analyzed according to the procedure described in Section 5.3.4.1. Spectral data are analyzed automatically using the ION alpha spectrum analysis program.

\subsubsection{X-ray/Gamma-ray Spectrometer}

Soil samples are prepared for analysis using the procedures described in Sections 5.3.2 and 5.3.3.2 and then loaded into one of the sample changer magazines. The sample identification number is entered into the XGAP program. After all of the samples are loaded into magazines of the sample changer and their identilication numbers entered into XGAP, the count que is started. All samples entered into the XGAP program count que are analyzed automatically.

The chi-square and amount of gain or zero shift necessary to obtain an optimum fit for the $\mathrm{L} x$-ray components are included in the printout of the plutonium and ${ }^{241} \mathrm{Am}$ activities or activity concentrations and are measures of the quality of the fit of the components to the spectral data. The uncertainties in the activities or activity concentrations determined using the LXRAY program are currently underestimated.

The activities of gamma-ray emitting radionuclides are determined by analyzing specific gamma-ray energy regions of the spectrum using the VAXGAP program. The results of these fitted regions are reported with their uncertainties whether positive or negative.

\subsubsection{Alpha Continuous Air Monitor}

Each alpha CAM sample filter is installed in the CAM filter holder and spectrum accumulation initiated following the procedures described in Section 5.3.4.3. For each of the four alpha CAMs, the cumulative alpha spectrum is analyzed at regular intervals during sampling, and the average airborne TRU concentration calculated for each counting interval is plotted on the alpha CAM monitor immediately following completion of the spectrum analysis. Spectrum analysis is performed using the ACAM program and the spectrum analysis algorithm described in Section 4.3.3.

\subsection{Calculation Procedures}

In the case of the large-area ionization chamber and germanium spectrometers, activities in each sample are calculated automatically using the spectrum analysis programs ION and XGAP, respectively. In the case of the alpha CAMs, airborne TRU concentrations are automatically calculated and plotted using the ACAM program. The three spectrum analysis programs are installed on the VAX computer in the RTML analysis trailer. 
For the large-area ionization chamber alpha spectrometers, the net area of each TRU alpha peak is determined by subtracting from the gross counts in the peak the counts contributed by instrument background and the low-energy tails of the ${ }^{218} \mathrm{Po} /{ }^{212} \mathrm{Bi}$ and ${ }^{214} \mathrm{Po}$ peaks. In the case of soil samples, activity concentration, $\mathrm{C}_{\mathrm{l}}$, expressed as $\mathrm{pCi} / \mathrm{g}$ is calculated as

$$
C_{i}=\frac{C_{G}-B_{i}-\left(k_{1} \cdot R_{1}\right)-\left(k_{2} \cdot R_{2}\right)}{2.22 \cdot \epsilon \cdot T \cdot M}
$$

where

$$
\begin{aligned}
& \mathrm{C}_{\mathrm{G}}=\text { total counts in TRU alpha peak (counts) } \\
& \mathrm{B}_{\mathrm{i}} \quad=\text { instrument background in TRU alpha peak (counts) } \\
& k_{1}=\text { fraction of counts in background } \mathrm{ROI}, \mathrm{R}_{1} \text {, that fall in energy region of TRU alpha } \\
& \mathrm{R}_{1}=\mathrm{ROI} \text { encompassing }{ }^{218} \mathrm{Po} /{ }^{212} \mathrm{Bi} \text { peak } \\
& k_{2}=\text { fraction of counts in background } \mathrm{ROI}, \mathrm{R}_{2} \text {, that fall in energy region of TRU alpha } \\
& \text { peak } \\
& \mathrm{R}_{2}=\text { ROI encompassing }{ }^{214} \text { Po peak } \\
& 2.22=\text { number of disintegrations per minute per } \mathrm{pCi} \\
& \epsilon \quad=\text { absolute counting efficiency (counts per disintegration) } \\
& T=\text { count time (minutes) } \\
& \mathrm{M} \quad=\text { sample mass }(\mathrm{g}) \text {. }
\end{aligned}
$$

In the case of the $x$-ray/gamma-ray spectrometer, the net number of counts in each $L$ x-ray peak is determined using the LXRAY subroutine of the XGAP program, and the net number of counts in each gamma-ray peak is determined using the VAXGAP subroutine of the XGAP program. For a soil sample, activity concentration, $\mathrm{C}_{X}$, expressed as $\mathrm{pCi} / \mathrm{g}$, is calculated as

$$
\mathrm{C}_{\mathrm{x}}=\frac{\mathrm{C}_{\mathrm{N}}}{2.22 \cdot \mathrm{P} \cdot \mathrm{\epsilon} \cdot \mathrm{T} \cdot \mathrm{M}}
$$


where

$$
\begin{aligned}
& \mathrm{C}_{\mathrm{N}}=\text { net counts in } \mathrm{x} \text {-ray or gamma-ray peak } \\
& \mathrm{P}=\text { emission probability of } \mathrm{x} \text {-ray or gamma ray. }
\end{aligned}
$$

Other terms are defined in Equation 4.

For the gridded ionization counter and the L x-ray/gamma-ray spectrometer, the value of $\epsilon$ is determined by calibration with a sample whose activity is known. However, in the case of the measurement of plutonium and americium by the measurement of their emitted L x-rays, a standardization coefficient is determined instead of an efficiency. The standardization coefficient is the ratio of the radionuclide component from the sample to that from the standard correcting for differences in counting time, mass of a soil sample, or volume of air through a filter.

In the case of the alpha CAMs, the airborne TRU concentration during the first counting interval, $\mathrm{X}_{1}$, expressed as $\mathrm{pCi} / \mathrm{L}$, is calculated as

$$
\mathrm{X}_{1}=\frac{\mathrm{C}_{1}}{2.22 \cdot \epsilon \cdot \mathrm{Y} \cdot \mathrm{F} 1 \cdot \frac{\mathrm{T}_{1}{ }^{2}}{2}}
$$

where

$\mathrm{C}_{1}=$ net counts in TRU alpha peak during lirst counting interval (counts)

$\mathrm{Y}=$ activity collection efliciency of CAM

$\mathrm{F}_{1}=$ average tlow rate during first counting interval $(\mathrm{L} / \mathrm{min})$

$\mathrm{T}_{1}=$ length of first counting interval (min).

The airborne TRU concentration during the second counting interval is calculated as

$$
X_{2}=\frac{C_{2}-C_{1}-2 C_{1}\left(T_{2} / T_{1}\right)}{2.22 \cdot \epsilon \cdot Y \cdot F_{2} \cdot \frac{T_{2}^{2}}{2}}
$$

where

$\mathrm{C}_{2}=$ net counts in TRU alpha peak at end of second counting interval (counts)

$F_{2}=$ average flow rate during second counting interval $(\mathrm{L} / \mathrm{min})$

$T_{2}=$ length of second counting interval (min). 
The airborne TRU concentration during each subsecfuent counting interval, $X_{11}$, expressed as $\mathrm{pCi} / \mathrm{L}$, is calculated as

$$
X_{n}=\frac{\left(C_{n}-C_{n-1}\right)-\left(C_{n-1}-C_{n-2}\right)\left(T_{n} / T_{n-1}\right)}{2.22 \cdot \epsilon \cdot Y \cdot F n \cdot \frac{T_{n}^{2}}{2}}-X_{n-1} \cdot\left(T_{n-1} / T_{n}\right)\left(F_{n-1} / F_{n}\right)
$$

where

$\mathrm{C}_{\mathrm{n}}=$ net counts in TRU alpha peak at end of counting interval n (counts)

$\mathrm{F}_{\mathrm{n}}=$ average llow rate during counting interval $\mathrm{n}(\mathrm{L} / \mathrm{min})$

$T_{n}=$ length of counting interval $n$ (min). 


\section{DATA MANAGEMENT AND ANALYSIS}

Aspects of data management and analysis discussed in this section include data reduction, validation, recording, and calculations. Copies of all raw and validated data will be stored on the RMTL VAX 4000. Backup copies of all data will be downloaded to the BWID Data Management System.

\subsection{Reduction, Validation, and Recording}

Data collected during the demonstration will be evaluated and documented in an EG\&G Idaho informal report. Data included in the report will be qualified by the principal investigators and will be subjected to peer review. Data obtained during the demonstration that will be presented in the report include

- LLD activities or concentrations of ${ }^{239} \mathrm{Pu}$ and ${ }^{241} \mathrm{Am}$ in soils, smears, and airborne dust determined for the large-area ionization chamber alpha spectrometers

- LLD activities or concentrations of plutonium, ${ }^{241} \mathrm{Am},{ }^{60} \mathrm{Co}$, and ${ }^{137} \mathrm{Cs}$ in soils, smears, and airborne dust determined for the $\mathrm{x}$-ray/gamma-ray spectrometer

- LLD concentration of airborne ${ }^{239} \mathrm{Pu}$ determined for each of the four alpha CAMs

- Sample throughput rates for the large-area ionization chamber spectrometers and the $\mathrm{x}$-ray/gamma-ray spectrometer.

In addition, the report will present qualitative assessments of

- RTML hardware and software performance

- Procedures used to collect, prepare, and analyze soil, smear, and airborne dust samples.

\subsection{Data Calculations}

Radionuclide concentrations in soil and air will be calculated using the methods described in Section 8.2. LLD activities and concentrations will be calculated at the $95 \%$ confidence level using Currie's methodology ${ }^{23}$ described in Section 5.8. 


\section{QUALITY ASSURANCE}

\subsection{Quantitative Quality Assurance Objectives}

Quality assurance goals include producing field-deployable measurentent systems that will satisly project measurement sensitivity requirements. As described in Section 5.4, the methodelogy of Currie ${ }^{23}$ was used to calculate, at the $95 \%$ conlidence level, the LLDs of the measurement systems. Estimated LLDs of the x-ray/gamma-ray spectrometer for plutonium, americium, and gamma-raly emilting radionuclides are given in Table 1 for the case of 12-g soil samples counted for 30) minules. LLDs of the large-area ionization chamber alpha spectromelers for alpha-emitting TRU isotopes in soil and air are estimated to be $50 \mathrm{pCi} / \mathrm{g}$ and $(0.1 \mathrm{DAC}-\mathrm{h}$, respectively, using counting times of 10 minutes. LLDs of the alpha CAMs for airborne ${ }^{239} \mathrm{Pu}$ and ${ }^{241} \mathrm{Am}$ are estimated (o) be less than 8 DAC-h using a spectrum analysis interval of 30 minutes.

The precision of measurements made using the large-area ionization chamber alpha spectromelers, $x$-ray/gamma-ray spectrometer, and alpha CAMs is dictated primarily by Poisson statistics and the uncertainty of hackground estimates. Therefore, instrument precision is dependent on factors such as quantity of activity present in the sample and the counting lime used to analyze the sample. Instrument precision will be determined in the field by analyzing given standards multiple limes.

The accuracy of measurements made using the RMTL measurement systems is dependent on counting statistics, uncertainty of estimated backgrounds, quantity of activity present in the sample, counting time, and uncertainties of parameters used to calculate isotope concentration such as sample preparation chemical yicld, sample mass or volume, and absolute counting efliciency. Instrument accuracy will be decermined in the field by analyzing traceable standards of the National Institute of Standards and Technology with sample geometries that are the same as the unknown samples.

\subsection{Replicate Blanks}

Most of the test samples will not contain alpha activity detectable in the specified counting times. Failure to detect activity in nonradioactive samples will demonstrate the capability of the analysis technique to not report false positive activities. Capability to accurately identify the radionuclides present in spiked samples and measure their activitics, when above LLDD, demonstrates the capability of the analysis technique to perform eorrect assays even on samples near the detection limit. Lower limits of detection will be calculated for the spectra obtained using the Currie methodology. 23

\subsection{Standards}

Standard soils ${ }^{25,26}$ containing known quantities of ${ }^{239} \mathrm{Pu}$ will be spotted randomly throughout the samples, some at levels only slightly higher than the expected lower limit of detection to validale its value, and some several times higher to evaluate the accuracy obtainable when better statistical precision can be achieved. Samples of air containing known quantities of alpha activity are more difficult and expensive (o prepare. The detection limit can be calculated from Currices equation, but 
some alternative will have to be devised to demonstrate the accuracy with which higher activities can be measured.

\subsection{Cross Contamination}

Cross contamination among samples is always a problem when large numbers of samples must be dried, sieved, and ground in proximity to one another using the same pans, sieves, pestle, and other nondisposable items. This is particularly true in a mobile laboratory without running water and sewage facilities. For this reason, the drying oven used is of the gravily-flow type, without lorecd air circulation, and as much spacing between sample pans will be maintained as is consistent with the work load to be accommodated. Disposable aluminum sample pans will be used. However, the pans will be reused to minimize waste disposal when the previous analysis indicates absence of signilicant activity in the sample contained in that pan. Nondisposable items such as sieves, pestle, etc. will be wiped with laboratory tissue until visually clean. It should be emphasized that mere presence of residual sample does not necessarily result in detectable contamination of the following sample. If $1,000 \mathrm{~g}$ samples are prepared for analysis and even $0.1 \mathrm{~g}$ of residual sample is allowed to remain on the pan, sieve, pestle, etc., the contamination of the subsequent sample will be diluted 10,000 fold following homogenization. If the detection limit were $50 \mathrm{pCi} / \mathrm{g}$, the previous sample would have to have contained $0.5 \mu \mathrm{Ci} / \mathrm{g}$ of activity to be detectable. It will not be difficult to avoid residuals as large as $0.1 \mathrm{~g}$. 


\section{SAFETY, TRAINING, AND LOGISTICS}

Sately is of utmost concern with all experiments. It is the policy of ECi\&( I latho lo lake every practical precaution to guard the health and safety of its employeces and gencral public. Three types of safely and training coneerns are emphasized: radiological, laboratory, and waste management. No one participating in the lield lest of the RTML will be allowed inside the lience of the Cold Test Pit area. Only radiation workers trained in the operation of rarliation measuring instrumentation will be used 10 operate the counting instrumentation. The sample preparation will be conducled by experienced radiochemists or performed under their direci supervision. Occupalional Safely and Health Administration (OSHA)/HAZWORKER training wil be obtained by all personnel who will collect samples from the Cold Test Pit. The work will be conducted under a Radiation Worker Permit. Accidents will be reported (o) the Cold Test Pit Facility Manager and the unit managers of the personnel conducting this lield test.

\subsection{Radiological Safety and Training}

Radiological saliety and conformance to the EG\&G Idaho Radiological Comerols Manual (RADCON) will be ensured by consulting on-duty RADCON personnel betore beginning work involving radioactive matcrials. Subsections of the manual that apply to this decument include

- Chapter 3, "Airborne Radioactivity Limits, HEPA Filter Requirements, Monitoring for Airborne Radicalctivity"

- Chapter 4, "Enclosure for Containing Contamination and Severe Mcasurements"

- Chapter 8. "Constant Air Monitors, Instrument Calibration and Control, Selection and Installation of Continuous Air Monitors"

- Chapter 11, "Continuous Availability of RADCON Personnel, Inspecling Radiological Work, Planning Radiological Controls, Radiation Worker Training, Radiological Controls, Revicw and Approval."

The radioactive samples being assayed consist of small quantitics of soil $(<25 \mathrm{~g})$, smears $(47 \mathrm{~mm}$ diameler lilter paper), and CAM filters that are contained within a 7() $\mathrm{mm}$ diameter $\times 8 \mathrm{~mm}$ thick plastic container with a snap on lid. Typical activitics or activity concentrations are $<110() \mathrm{pCi} / \mathrm{g}$ and $<5,(0)(0) \mathrm{pCi}$, respectively. Therefore, the radiological hazard is small and consists in potential contamination by very low-activity radioactive material and the possibility of a high-activity sample not being identilied by the up-stream screening performed with portable heallh physics (HP) instrumentation.

1. Hazards

a. Exposure by a high-activity sample not identified by up-stream monitoring with HP instrumentation. 
b. Spread of low-activity radioactive material due to leakage or by unsealed or broken containers.

\section{Precautions}

a. All samples will be monitored by HP instrumentation before released from the sample preparation trailer to be counted in the mobile laboratory trailer.

b. Samples will be sealed with sealant (e.g., super glue, RTV, or model airplane glue) or with transparent tape before handling. Prepared samples will be promptly loaded into the sample holder for most handling operations and will not be removed until all counting is complete.

c. The sample magazine shall always be held at an upward angle to prevent individual samples from sliding out of the sample holder magazine.

\subsection{Laboratory Safety and Training}

Laboratory safe practices are described in the EG\&G Idaho Science and Technology Standard Practices Manual, Section 2. Subsections that apply to this document in Section 2.1, "General Laboratory Practices," include

- 2.1.5, "Eye Protection and Protective Clothing"

- 2.1.6, "Laboratory Safety"

- 2.1.8, "Laboratory Hood Use."

Subsections that apply to Section 2.2, "Site Laboratory Practices," include

- 2.2.4. "Radioaclive Materials Handling"

- 2.2.7, "Laboratory Radiological Training."

The photon analysis spectrometer uses a liquid nitrogen $\left(\mathrm{LN}_{2}\right)$ cooled germanium spectrometer. The dewar that maintains the detector at $\mathrm{LN}_{2}$ temperatures is filled weekly, or when the operation requires, twice a week.

1. Hazards

a. Asphyxiation, if $\mathrm{LN}_{2}$ evaporates rapidly in a confined space. This is a very remote possibility even when dewars develop a vacuum leak.

b. Burns, if $\mathrm{LN}_{2}$ gets on tight fitting clothing, trapped in shoes or pockets, or gets on bare skin.

c. Explosion, if $\mathrm{LN}_{2}$ is confined without pressure relicf. 
2. Precautions

a. Protective equipment should be worn including leather or eryogenic gloves and goggles.

b. Piping and transfer lines should be constructed to avoid trapping of $\mathrm{LN}_{2}$ in the lines.

c. $\mathrm{LN}_{2}$ should be vented to a well ventilated room or to the outside whenever possible, or an oxygen depletion monitor should be used when ventilation is not adequate.

No electric circuits are exposed to the operator and most of the instrumentation operates on $+12,-12,+24$, and $-24 \mathrm{~V}$ circuits. Therefore, use of frayed cords or carcless operations such as operation with wet hands or unauthorized repairs, could result in electrical shock.

1. Hazards
a. Frayed power cords.
b. Operation with wet hands.

2. Precautions

a. Before every campaign or on the first day of each month that the photon analysis spectrometer is used, power cords should be checked for fraying especially near the electrical plug.

b. System should be operated with dry hands only.

Although no heavy lifting or extended reaching is involved in preparing or counting samples, various common physical hazards potentially exist. Most of these hazards are encountered in the sample preparation trailer and include cuts from sharp objects and burns from touching objects that were heated in the drying oven; however, eye strain, repetitive motions (carpal tunnel syndrome), and tripping hazards are also subtle concerns. Personnel involved in the in-field test demonstration should also be cautious of these hazards and take measures to avoid them. Personnel should exercise good office safety.

1. Hazards
a. High temperature
b. Sharp edges
c. Eye strain and repetitive motions. 
2. Precautions
a. Handle heate? objects with tongs or gloves.
b. Beware of any sharp objects that could inflect a wound.
c. Take 10 minute breaks from the computer console every hour.

\subsection{Waste Mariagement Practices and Training}

Waste management practices are prescribed in the EG\&G Idaho Safety Manual, Section 15, and the Science and Technology Standard Practices Manual, Section 2. Pertinent sections include

- 2.1.1, "Nonradioactive Chemical Waste Disposal"

- 2.1.3, "Chemical Lab Inventory"

- 2.1.4, "Chemical Spill Control"

and

- 2, "Incinerable Low-level Radioactive Waste"

- 3, "Compactible Low-level Radioactive Waste"

- 9, "Transuranic W.sste"

- 15.1, "Routine Solid Waste Collection and Handling." 


\section{REFERENCES}

1. P. G. Shaw et al., Test Plan for Contamination Control Related Experiments, EGG-WM-9059, March 1990.

2. G. G. Loomis and C. V. McIsaac, "Rapid Monitoring for Transuranic Contamination During Buried Waste Retrieval," Waste Processing, Transportation, Storage and Disposal, Technical Programs and Public Education, Volume I, Proceedings, Symposium on Waste Management at Tucson, Arizona, February 24-28, 1991:723-728, 1991.

3. G. G. Loomis, Technology Status Report Transuranic Contamination Control at INEL, EGG-WTD-9899, September 1991.

4. C. V. Mclsaac and C. R. Amaro, Real-time Transuranic Monitoring with a Victoreen Model 758 Alpha Continuous Air Monitor, EGG-WM-8774, September 1989.

5. C. V. McIsaac et al., "Sensitivities of Alpha Continuous Air Monitors for Detection of Airborne Pu-239." Waste Processing, Transportation, Storage and Disposal, Technical Programs and Public Education, Volume II, Proceedings, Symposium on Waste Management at Tucson, Arizona, February 24-28, 1991:695-705, 1991.

6. C. V. McIsaac et al., Rapid Monitoring for Transuranic Contaminants During Buried Waste Retrieval, EGG-WTD-9412, March 1991.

7. M. R. Winberg, Test Plan for FY-91 Alpha CAM Evaluation, EGG-WTD-9571, March 1991.

8. C. V. McIsaac and C. R. Amaro, Sensitivities of Five Alpha Continuous Air Monitors for Detection of Airborne Pu-2.39, EGG-WTD-10314, July 1992.

9. C. W. Sill and R. J. Gehrke, Test Plan for Rapid Transuranic Monitoring of Soil and Air Dusts by Direct Large-Area Alpha Spectrometry and L-Shell X-Ray Spectrometry, EGG-WTD-9735, May 1991.

10. C. W. Sill, Rapid Monitoring of Soil, Smears, and Air Dusts by Direct Large-Area Alpha Spectrometry, EGG-WTD-10080, January 1992.

11. R. J. Gritrke et al, "Rapid Assay of Plutonium in Soils by Passive L X-Ray Counting," Trans of the Amer Nucl Soc, 64:94, 1991.

12. C. W. Sill, "Rapid Monitoring of Soil, Water, and Air Dusts by Direct Large-Area Alpha Spectrometry," submitted to Health Physics, September 1992.

13. P. G. Voilleque et al., Development of Criteria for Release of Idaho National Enginecring Laboratory Siles Following Decontamination and Decommissioning, EGG-2400, August 1986. 
14. R. V. Osborne and C. R. Hill, "High Resolution Alpha Particle Spectroscopy at Very Low Specific Activities," Nucl Inst \& Methods 29:101-106, 1964.

15. H. Hotzl and R. Winkler, "Large Area Gridded Ionization Chamber and Electrostatic Precipitator. Application to Low-level Alpha Spectrometry of Environmental Air Samples," Nucl Inst \& Methods 150:177-181, 1978.

16. H. Hotzl and R. Winkler, "Experiences with Large Area Frish Grid Chambers in Low-level Alpha Spectrometry," Nucl Inst \& Methods in Phys Res 223:290-294, 1984.

17. L. Johansson, B. Roos, and C. Samuelsson, "Alpha-particle Spectrometry of Large-area Samples Using an Open-flow Pulse Ionization Chamber," Appl Radiat Isot 4.3:119-125, 1992.

18. J. K. Hartwell and S. G. Goodwin, "Pulser Injection with Subsequent Removal- Implementation and Applications," IEEE Trans on Nucl Sci, NS-36, No.1, 1989.

19. E. W. Killian and J. K. Hartwell, VAXGAP: A Code for the Routine Analysis of Gamma-Ray Pulse Height Spectra on a VAX Computer, EGG-2533, May 1988.

20. E. W. Killian and D. A. Femec, An Operator's Guide to VAXGAP, Rev. 2.0, ST-CS-031-90, November 1990.

21. G. K. Rusch, W. P. McDowell, and W. G. Knapp, "The ZPR-9 Airborne Plutonium Monitoring System," IEEE Tran on Nucl Sci, Vol.NS-23, No.1:690-692, 1976.

22. T. J. Yule, "An On-Line Monitor for Alpha-Emitting Aerosols," IEEE Tran on Nucl Sci, Vol.NS-25, No.1:762-766, 1978.

23. L. A. Currie, "Limits for Qualitative Detection and Quantitative Determination," Anal Chem 40:586-593, 1968.

24. C. W. Sill, "Precipitation of Actinides as Fluorides or Hydroxides for High-Resolution Alpha Spectrometry," Nucl and Chem Waste Management, Vol.7:201, 1987.

25. C. W. Sill and F. D. Hindman, "Preparation and Testing of Standard Soils Containing Known Quanities of Radionuclides," Anal Chem 46:113-118, 1974.

26. C. W. Sill, "Long-term Stability of Solid Standards for Radiochemical Analysis," Anal Chem 61:2255-2258, 1989. 

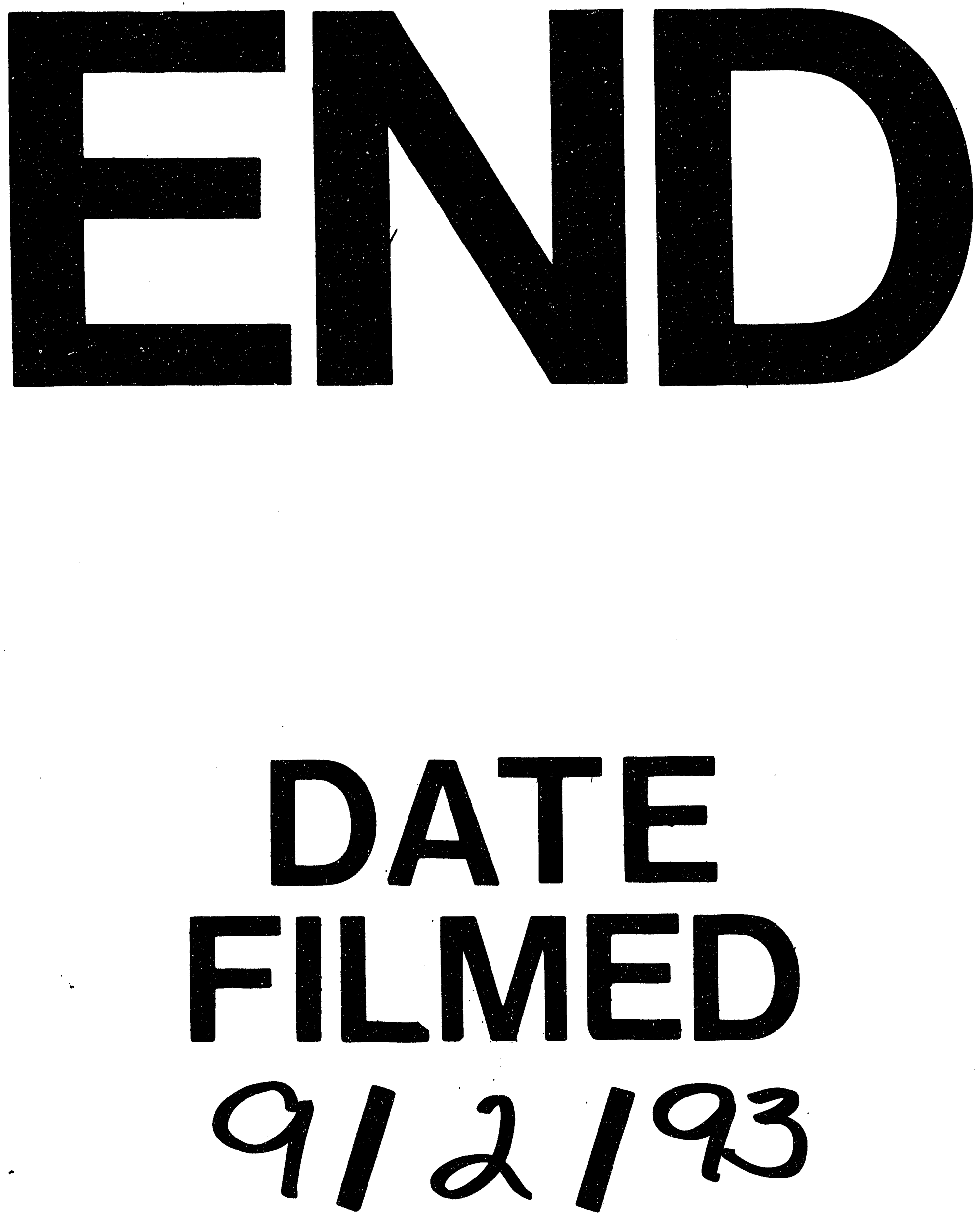
